\title{
Opioid and non-opioid analgesic prescribing before and after the CDC's 2016 opioid guideline
}

\author{
William Encinosa ${ }^{1}$ (D) Didem Bernard ${ }^{1} \cdot$ Thomas M. Selden $^{1}$
}

Received: 29 July 2020 / Accepted: 26 April 2021 / Published online: 8 May 2021

(C) This is a U.S. government work and not under copyright protection in the U.S.; foreign copyright protection may apply 2021

\begin{abstract}
The U.S. has addressed the opioid crisis using a two-front approach: state regulations limiting opioid prescriptions for acute pain patients, and voluntary federal CDC guidelines on shifting chronic pain patients to lower opioid doses and non-opioids. No opioid policy research to date has accounted for this two-pronged approach in their research design. We develop a theory of physician prescribing behavior under this two-pronged incentive structure. Using the Medical Expenditure Panel Survey, we empirically corroborate the theory: regulations and guidelines have the intended effects of reducing opioid prescriptions for acute and chronic pain, respectively, as well as the predicted unintended effects-income effects cause regulations on acute pain treatment to increase chronic pain opioid prescriptions and the chronic pain treatment guidelines spillover to reduce opioids for acute pain. Moreover, we find that the guidelines worked as intended in terms of the reduced usage, with chronic pain patients shifting to non-opioids and also tapering opioid doses. For those who discontinued opioids under regulations and guidelines, we find no harm in terms of increased work limitations due to pain a year after discontinuing opioids. Finally, we observe an unexplained dichotomy-regulations reduce opioid use by causing fewer new starts, whereas guidelines reduce opioid use by discontinuing current users, with no impact on new starts.
\end{abstract}

Keywords Opioids $\cdot$ Physician prescribing behavior $\cdot$ Incentives $\cdot$ Guidelines

JEL Classification I18

William Encinosa

William.Encinosa@ahrq.hhs.gov

Didem Bernard

didem.bernard@ahrq.hhs.gov

Thomas M. Selden

thomas.selden@ahrq.hhs.gov

1 Division of Research and Modeling, Center for Financing, Access, and Cost Trends, Agency for Healthcare Research and Quality, and the McCourt School of Public Policy, Georgetown University, Rockville, MD, USA 


\section{Introduction}

Opioid misuse is still a national crisis, costing an estimated \$2.5 trillion between 2015 and 2018 in increased medical spending, lost productivity, lives lost due to overdoses, and more (Council of Economic Advisors, 2019). With the onset of the economic and social stress of the COVID-19 pandemic, 700,000 more opioid deaths are expected over the next few years (Kang, 2020). Prescription opioids can be an important tool for managing pain; yet, improper prescribing, including excessive dosages (Manchikanti et al., 2017; Rosenberg et al., 2018; Rudd et al., 2016) or extended use (Edlund et al., 2014; Paulozzi et al., 2014; Brat et al., 2018), has been an important contributor to the opioid crisis (Califf, 2016), and numerous state and federal efforts have been launched to alter physician prescribing practices (Adams \& Giroir, 2019; Delcher et al., 2019). Due in part to these public efforts, the U.S. experienced a decline in prescription opioid use beginning in 2012 and accelerating after 2015 (Bohnert et al., 2018; Olaughlin \& Brantlye, 2018; Schieber et al., 2019).

These aggregate declines, however, have raised concerns that reductions affected populations for whom opioid use is appropriate and may have too often involved the abrupt discontinuation of use among patients with opioid dependencies (Dowell et al., 2019). State and federal policy efforts have encountered difficult choices regarding what to do with opioid users with chronic pain. Almost all recent state opioid policy regulations that limit prescription opioid quantities have exempted patients with chronic pain from their regulations (National Conference of State Legislatures, 2019; Davis et al., 2019). To specifically address patients with chronic pain, at the federal level the Centers for Disease Control and Prevention (CDC) released the "Guideline for Prescribing Opioids for Chronic Pain" in 2016 to deal with the concern that high dosages and long-term use of opioids for chronic pain can lead to opioid use disorder and its adverse health outcomes (Dowell et al., 2016). Expanding on earlier evidence from the Agency for Healthcare Research and Quality (AHRQ) on the low effectiveness of opioids in treating chronic pain (outside of cancer care and palliative care), the CDC Guidelines recommended reduced use of opioids among those with non-cancer chronic pain, with a preference for non-opioid analgesics (Chou et al., 2014). While previous research has shown that these federal and state regulations have played a key role in the recent aggregate reductions in opioid use (Kaestner \& Ziedan, 2019; Olaughlin \& Brantlye, 2018), we know very little about the differential impact of regulations on patterns of opioid and non-opioid analgesic use for those with and without chronic pain.

In this paper, we use nationally representative data from AHRQ's Medical Expenditure Panel Survey (MEPS) to fill several key gaps in the literature on how public policy altered prescription opioid use. First, MEPS conditions data enable us to track trends in opioid prescriptions separately for adults with and without (non-cancer) chronic pain. Second, by following individuals across the two years they participated in the survey, we can trace the dynamics of prescription opioid use, including opioid initiation, continuation among new users, and persistence, tapering, and substitution of non-opioid analgesics among long-term opioid users with chronic pain. Third, because MEPS data are nationally representative and collected consistently over time, they allow us to examine the extent to which recent state and federal opioid prescribing policies were associated with changes in these dynamic patterns of opioid use. 


\section{Background on the opioid epidemic}

In 2000, the U.S. Congress passed H.R. 3244, establishing 2000-2010 as the "Decade of Pain Control and Research" (Brennan, 2015). The aim was to improve pain management, especially for chronic pain, which was often thought by many pain experts to be undertreated during the 1990s. The Joint Commission on Accreditation of Healthcare Organizations (JCAHO) soon came out with new, more aggressive pain treatment standards requiring physicians to assess pain along with other vital sign during medical visits, as the "Fifth Vital Sign." The average consumption of opiates per patient quickly increased by $15 \%$ from 2000 to 2002 at the Mayo Clinic, with the greatest increase in the post anesthesia care unit (PACU) (62\%). This was hailed as an initial victory (Baker, 2017). However, this increase in opioids accelerated at a faster pace than ever expected. By the end of the decade in 2011, the CDC had to officially declare that the U.S. was in the midst of opioid epidemic. By 2010, the MMEs (morphine milligram equivalents) prescribed per person was more than 4 times as high as in 1999, 782 versus 180. Based on the Drug Enforcement Agency's data, the typical prescription from 2006 to 2012 would have totaled 123 MME a day-an amount $37 \%$ above the maximum recommended by the CDC, $90 \mathrm{MME}$ a day. Compared to a 20 MME dose per day, a 90 MME dose per day increases the risk of overdose death tenfold (Schuchat et al., 2017).

As a result, U.S. hospitalizations for opioid and heroin poisoning increased almost fivefold from 7000 in 2000 to 34,000 in 2011 (Song, 2017). Annual drug overdose deaths almost doubled from 19,800 in 2000 to 38,300 in 2010 and the increase in deaths has continued unabated. In 2019, there were 70,630 drug overdose deaths (Hedegaard et al., 2020), and by 2020, this has spiked to 90,000 annual deaths (Mattson et al., 2021). Roughly two thirds of the deaths are due to opioids, and one third of those opioid deaths are due to prescription opioids (Scholl et al., 2018). While the other third of opioid deaths are due to heroin, nearly $80 \%$ of recent heroin users reported using prescription opioids prior to heroin (Lankenau et al., 2012; Cicero et al., 2014; Jones, 2013; Muhuri et al., 2013). The final third of opioid deaths are due to illicit synthetic opioids (e.g., fentanyl). These are often combined with prescription opioids. Deaths from this combination have increased five-fold from 0.3 deaths per 100,000 capita in 2013 to 1.5 deaths per 100,000 in 2019 (Mattson et al., 2021).

This epidemic has multiple likely causes. Firstly, the Great Recession of 2008 has been blamed for creating an environment of despair ripe for opioid misuse. Sacks et al., (2019) report a positive association between county-level unemployment and opioid-involved overdose deaths - a 1-percentage-point increase in a county's unemployment rate is associated with a 0.19 -person increase in the rate of opioids involved in overdose deaths per 100,000. However, Bernard et al., (2020) found that the employed were more likely to start opioids. Also, the bulk of the opioid deaths occurred in large states with low unemployment rates. Overall, Currie and Schwandt (2020) conclude that economic distress did not cause the opioid epidemic.

What has received less attention as one main driving cause of the epidemic has basically been the creation of a new market-the chronic pain pharmaceutical market. Before the epidemic, there was no dearth of opioids for acute pain. In fact, in 1980, acute pain was so often treated with opioids that propoxyphene was the second-most dispensed prescription drug in the United States. The Carter White House declared, "Diversion, misuse, and abuse of legal drugs may be involved in as many as seven out of ten reports of drug-related injury or death" (Dasgupta et al., 2018). But, noncancer chronic pain was managed largely with 
cognitive behavioral therapy, even hypnosis. Pain advocates began to recommend opioids for chronic pain on a long term basis. Addiction was not a concern due to a pair of influential studies that found little evidence of risk. A now infamous one-paragraph letter in the New England Journal of Medicine in 1980 found that among a large sample of 11,882 hospitalized patients given opioids, only four developed addiction (Porter \& Jick, 1980). Another paper found no opioid addiction among 10,000 burn patients (Perry \& Heidrich, 1982). Pain advocacy groups incorrectly assumed these acute pain results applied to outpatient chronic pain patients. In 1990, the President of the American Pain Society wrote an editorial in the Annals of Internal Medicine creating the chronic pain treatment movement of the 1990s, citing the 1980 article to claim that the "therapeutic use of opiate analgesics rarely results in addiction" (Max, 1990). Amidst this environment, Purdue Pharma set out to create a chronic pain management market outside of cancer care for opioids (reference?). In 1990, facing expiration of the patent for their MS Contin opioid (time-released morphine), they created OxyContin (time-released oxycodone, which is $50 \%$ stronger than morphine). They marketed it as being rarely addictive, citing only the two 1980 studies above in their promotional material. In 1995, the FDA approved it with the label "safer than other opioids," and addiction "very rare," without any clinical evidence. OxyContin quickly became a blockbuster drug for chronic pain, with little competition. Withdrawals from the market of popular nonopioid analgesics (NSAIDs) because of cardiovascular risk and acetaminophen toxicity raised doubts about the effectiveness of nonopioid alternatives (Dasgupta et al., 2018). And, due to the obesity epidemic, the incidence of noncancer chronic pain was increasing dramatically. By 2011, the Institute of Medicine's Report, Relieving Pain in America, claimed that "chronic pain affects about 100 million American adults - more than the total affected by heart disease, cancer, and diabetes combined." While this was quite exaggerated, the FDA was even still using this statistic in 2014 for their press release for the approval of the opioid Zohydro.

The creation of this large, new chronic pain drug market was further fueled by extremely low drug prices. Between 2000 and 2016, the price of prescription opioids declined by 45\% due to generic entry. More importantly, between 2000 and 2010 the out-of-pocket price of opioids fell by $81 \%$. This was mainly driven by the implementation of Medicare Part D in 2006. The number of potency-adjusted opioids per capita subsidized by Medicare increased by 2,400\% between 2001 and 2010. In 2007, uninsured Americans could buy $1 \mathrm{~g}$ of OxyContin for an average of $\$ 144$. An uninsured person with an opioid use disorder consuming between $0.5 \mathrm{~g}$ and $1 \mathrm{~g}$ of OxyContin every day for a year would have had to spend between $\$ 26,280$ and $\$ 52,560$ in 2007-an amount that was than the median household income of about $\$ 50,000$ in that year (in 2007 dollars). In contrast, a person enrolled in the new Medicare Part D in 2007 would have paid only $\$ 9.78$ per gram, or between $\$ 1785$ and $\$ 3570$ per year to pay for the same level of consumption. Opioids had become very affordable (Council of Economic Advisors, 2020).

Unfortunately, opioids were not as safe as expected for treating chronic pain. OxyContin was intended to be continuously taken by chronic pain patients at the rate of two pills per day (Contin = continuous). However, OxyContin often only lasted $8 \mathrm{~h}$, not $12 \mathrm{~h}$ (Keefe, 2017) Thus, by 2004, 20\% of the prescriptions now gave 3 pills a day instead of 2 a day. Many overdoses and deaths resulted. Purdue had marketed it to primary care physicians, who were not trained in pain management and addiction. By 2004, half of all OxyContin prescriptions were written by primary care physicians (Van Zee, 2009). The International Association for the Study of Pain (IASP) defines chronic pain as "pain that persists beyond normal tissue healing time, which is assumed to be three months." However, we now know that, even for low doses, using opioids for more than three 
months increases the risk of addiction 15-fold (CDC 2017). Between 8 and 12\%percent of people using an opioid for chronic pain develop an opioid use disorder (Vowles et al., 2015).

Moreover, it was becoming clear that opioids were not effective for noncancer chronic pain. For example, the 2014 National Institutes of Health Pathways to Prevention workshop found insufficient evidence "to determine the effectiveness of long-term opioid therapy for improving chronic pain and function" but did find evidence of a "dosedependent risk for serious harms" (Chou et al., 2015). These results were echoed in a 2014 AHRQ Evidence Report (Chou et al., 2014). About the same time, the American Medical Association and the American Academy of Family Physicians voted to rescind their previous support of pain as the 5th Vital Sign (Ballantyne \& Sullivan, 2015). In 2016, the CDC issued the "Guideline for Prescribing Opioids for Chronic Pain," with twelve main points directed toward primary care clinicians. Firstly, it stresses that opioids are not first-line medications for the treatment of chronic pain. Nonpharmacologic therapy and nonopioid pharmacologic therapy are preferred for chronic pain. Secondly, if opioids are prescribed for chronic pain, they should rarely be increased above 50 MME, avoiding going beyond 90 MME. Thirdly, the patient should be evaluated every three months. If the patient has not improved in pain and function by $30 \%$, the opioid should be tapered and discontinued (Dowell et al., 2016). The goal of the guidelines was to train primary care clinicians in treating chronic pain with opioids. According to a 2011 study, many medical schools at that time offered less than $5 \mathrm{~h}$ of training in pain management to their students (Mezei \& Murinson, 2011). Only a third of physicians felt adequately trained to manage patients with chronic pain (Yanni 2010; Compton and Jones 2019).

The CDC Guideline did not address opioids for acute pain. At about the same time there were several State regulations to limit the supply of opioids for acute pain. To reduce leftover opioids, at least 35 states have now implemented limits that restrict either the duration or number of doses in opioid prescriptions for acute pain (Chua \& Kimmel, 2020). Next, a Prescription Drug Monitoring Program (PDMP) is a centralized database containing a record of all of a patient's prescription opioids. PDMPs are designed to increase the sharing of information across providers who may potentially prescribe opioids to the same patient. By 2017, all states had a PDMP. However, only thirteen states had a comprehensive PDMP mandate, which must meet the following criteria as defined by Wen et al., (2019): "All providers... are subject to the mandate; providers are required to check the program upon initial prescribing and at least every twelve months...; and providers are not allowed to rely on their own judgment to determine whether it is necessary to check the program in individual cases." Finally, several states have implemented Pill Mill laws. These laws set up strict regulations on physicians having more than $50 \%$ of their patients on opioids (e.g., "pill mills"). They are required to operate as a regulated, licensed pain management clinics.

All of these state regulations have had some impact on reducing the opioid crisis. See Maclean et al., (2020) for a review of the economic evidence. Overall, dispensing of opioid prescriptions has declined $43 \%$ from the peak in 2012 at 81.3 per 100 persons to 46.7 per 100 in 2019 (CDC 2020). This was accompanied by a $41 \%$ decline in the overdose death rate for prescription opioids not combined with illicit synthetic opioids, from 4.1 deaths per 100,000 people in 2013 to 2.4 deaths per 100,000 in 2019 (Mattson et al., 2021). However, what has not been studied by the literature has been the relative magnitude in the decline in opioids for chronic pain versus acute pain. Nor have researchers examined the differential impact of the CDC guidelines and state regulations on opioids for both chronic and acute pain during the opioid epidemic. This is the topic that we address in this paper. 


\section{Theoretical model}

Here we develop a simple theoretical model to guide our empirical examination of how state regulations and federal CDC guidelines might impact physician prescribing behavior for opioids. We adapt the seminal physician model of Ellis and McGuire (1986) to opioids by introducing two quantities: $\mathrm{q}_{\mathrm{a}}$ the quantity of opioid prescriptions for the doctor's acute pain patients, and $\mathrm{q}_{\mathrm{c}}$, the quantity of opioid prescriptions for the doctor's chronic pain patients. The physician will select $\mathrm{q}_{\mathrm{a}}$ and $\mathrm{q}_{\mathrm{c}}$ to maximize her utility over profit and patient welfare, U(profit, welfare):

$$
U\left(\pi_{a}\left(q_{a}, R\right)+\pi_{c}\left(q_{c}\right), V_{a}\left(q_{a}\right)+V_{c}\left(q_{c}, G\right)\right),
$$

where $\pi_{\mathrm{i}}$ is the physician's profit on the quantity of opioid prescriptions $\mathrm{q}_{\mathrm{i}}$ and $\mathrm{V}_{\mathrm{i}}$ is the aggregate value the patients get from such a quantity ( $i=a$, acute pain; $i=c$, chronic pain). Note that the physician may increase $q_{i}$ by either writing another prescription to continue a patient on opioids, or by starting a new patient on opioids. $\mathrm{R}$ is state regulation on the prescribing of opioids for acute pain, and G are CDC guidelines on prescribing for chronic pain. $\mathrm{R}$ is defined on $[0,1]$, indexing the strictness of state regulations on opioid prescribing for acute pain, such that the profit $\pi_{\mathrm{a}}$ on acute pain patients declines in R. For example, as state limits on opioid quantities for acute pain become more severe, it is more costly for the physician in time and effort to try to increase quantities. $G$ is defined on $[0,1]$, indexing the persuasiveness of the CDC Guidelines on opioid prescribing for chronic pain. That is, we assume that as $\mathrm{G}$ increases, $\mathrm{V}_{\mathrm{c}}$ declines, in the sense that the physician sees that the patient's value from the opioids is less than she previously thought (e.g., the risk of addiction is larger than previously thought).

Assumptions For simplicity, we will also assume that the corresponding marginal profit and marginal value are also declining or constant in the policies: $\mathrm{d}^{2} \pi_{\mathrm{a}} / \mathrm{dq}_{\mathrm{a}} \mathrm{dR}<=0$ and $\mathrm{d}^{2} \mathrm{~V}_{\mathrm{c}} / \mathrm{dq}_{\mathrm{c}} \mathrm{dG}<=0$. We assume that utility $\mathrm{U}$ is concave, with $\mathrm{U}_{11}<0$ and $\mathrm{U}_{22}<0$. For simplicity, we assume separable utility, $\mathrm{U}_{12}=0$ (all results below hold more generally for complements, $\mathrm{U}_{12}>=0$ ). We also assume that $\pi$ and $\mathrm{V}$ are concave with an existing maximum (e.g., at high levels of $q, V$ declines, reflecting the risks and harms of addiction). Define $q_{i}{ }^{\text {' }}$ to be the quantity that maximizes $\pi_{\mathrm{i}}$, and define $\mathrm{q}_{\mathrm{i}}$ ', to be the quantity that maximizes $\mathrm{V}_{\mathrm{i}}$. Let $\mathrm{q}_{\mathrm{a}}{ }^{*}$ and $\mathrm{q}_{\mathrm{c}}{ }^{*}$ be the optimal quantities that maximize the overall physician utility $\mathrm{U}$ in (1), solving the first order conditions below:

$$
\frac{\partial U}{\partial q_{i}}=U_{1} \frac{\partial \pi_{i}}{\partial q_{i}}+U_{2} \frac{\partial V_{i}}{\partial q_{i}}=0, i=a, c .
$$

Next, assume simple profit specifications: $\pi_{a}(q, R)=p q-R b c(q)$ and $\pi_{c}(q)=p q-b d(q)$ for reimbursement $\mathrm{p}$, cost parameter $\mathrm{b}>0$, and convex cost functions $\mathrm{c}$ and $\mathrm{d}$. Then we have the following result.

Proposition 1 If reimbursement is high enough andlor costs low enough, the physician will overprescribe opioids: $q_{i}{ }^{\prime}<q_{i}{ }^{*}$ for $i=a, c$.

Proof By concavity of profit, $\mathrm{q}_{\mathrm{a}}$ ' will solve $\mathrm{c}^{\prime}(\mathrm{q})=\mathrm{p} / \mathrm{bR}$ and $\mathrm{q}_{\mathrm{c}}{ }^{\prime}$ will solve $\mathrm{d}^{\prime}(\mathrm{q})=\mathrm{p} / \mathrm{b}$. By convexity of $\mathrm{c}$ and $\mathrm{d}$, we have c' and d' increasing in $\mathrm{q}$, so that $\mathrm{q}_{\mathrm{i}}{ }^{\prime}$ is increasing in the ratio $\mathrm{p} / \mathrm{b}$. Thus, for a given $\mathrm{q}_{\mathrm{i}}{ }^{\prime}, \mathrm{i}=\mathrm{a}, \mathrm{c}$, there is a $\mathrm{p}$ large enough or $\mathrm{b}$ low enough, such that the 
ratio $\mathrm{p} / \mathrm{b}$ is large enough so that $\mathrm{q}_{\mathrm{i}}{ }^{\prime}>\mathrm{q}_{\mathrm{i}}{ }^{\prime}$ ' for $\mathrm{i}=\mathrm{a}, \mathrm{c}$. From (2) we see that $\mathrm{q}_{\mathrm{i}}{ }^{*}$ is a weighted average of $\mathrm{q}_{i}$ ' and $\mathrm{q}_{\mathrm{i}}$ '. Thus, $\mathrm{q}_{\mathrm{i}}{ }^{\prime}>\mathrm{q}_{\mathrm{i}}$ ' 'implies that $\mathrm{q}_{\mathrm{i}}{ }^{\prime}>\mathrm{q}_{\mathrm{i}}{ }^{*}>\mathrm{q}_{\mathrm{i}}$ ' for $\mathrm{i}=\mathrm{a}, \mathrm{c}$. That is, we then have overprescribing at $\mathrm{q}_{i}{ }^{*}$ for $\mathrm{i}=\mathrm{a}, \mathrm{c}$.

\section{Comparative statics in an overprescribed State of the World}

Let us assume we are in an overprescribed state of the world as in Proposition 1 (equivalent to assuming $\mathrm{q}_{\mathrm{i}}$ " $<\mathrm{q}_{\mathrm{i}}$ ' for $\left.\mathrm{i}=\mathrm{a}, \mathrm{c}\right)$. In this "overprescribed" state of the world, we then ask what happens to optimal opioid quantities $\mathrm{q}_{\mathrm{i}}$ * when we increase the regulation $\mathrm{R}$ on acute pain and increase guidelines $\mathrm{G}$ on chronic pain. First, define $m_{i}=\frac{-\partial^{2} U}{\partial q_{i} \partial q_{i}}>0, \mathrm{i}=\mathrm{a}, \mathrm{c}$. Then, totally differentiating (2) and using the Implicit Function Theorem, we have the following four policy comparative statics in $\mathrm{R}$ and $\mathrm{G}$ at $\mathrm{q}_{\mathrm{i}}{ }^{*}, \mathrm{i}=\mathrm{a}$, c, in (3)-(6) below. To sign the inequalities in these comparative statics, note that at $\mathrm{q}_{\mathrm{i}}{ }^{*}$ we are in a state of the world where physicians are "overprescribing" (beyond the maximum for $\mathrm{V}$ ) but not quite yet maximizing profit: $\mathrm{q}_{\mathrm{i}}{ }^{\prime}<\mathrm{q}_{\mathrm{i}}{ }^{*}<\mathrm{q}_{\mathrm{i}}$ ' for $\mathrm{i}=\mathrm{a}, \mathrm{c}$. This will then imply due to concavity that $\frac{\partial \pi_{i}}{\partial q_{i}}>0$ and $\frac{\partial V_{i}}{\partial q_{i}}<0$ at $\mathrm{q}_{\mathrm{i}}^{*}, \mathrm{i}=\mathrm{a}, \mathrm{c}$.

$$
\begin{gathered}
\frac{d q_{c}^{*}}{d R}=\frac{1}{m_{c}}\left(U_{11} \frac{\partial \pi_{c}}{\partial q_{c}} \frac{\partial \pi_{a}}{\partial R}\right)>0, \\
\frac{d q_{a}^{*}}{d R}=\frac{1}{m_{a}}\left(U_{11} \frac{\partial \pi_{a}}{\partial q_{a}} \frac{\partial \pi_{a}}{\partial R}+U_{1} \frac{\partial^{2} \pi_{a}}{\partial q_{a} \partial R}\right)>0 \text { or }<0, \\
\frac{d q_{c}^{*}}{d G}=\frac{1}{m_{c}}\left(U_{22} \frac{\partial V_{c}}{\partial q_{c}} \frac{\partial V_{c}}{\partial G}+U_{2} \frac{\partial^{2} V_{c}}{\partial q_{c} \partial G}\right)<0, \\
\frac{d q_{a}^{*}}{d G}=\frac{1}{m_{a}}\left(U_{22} \frac{\partial V_{a}}{\partial q_{a}} \frac{\partial V_{c}}{\partial G}\right)<0 .
\end{gathered}
$$

These comparative statics reveal three incentive effects of regulations and guidelines:

\section{Direct effects}

These are the intended effects as seen in (4) and (5). Regulations on acute pain opioids will cause quantities to decline for acute pain (if income effects $\left(U_{11}\right)$ are low) in (4). And, in (5), guidelines on opioids for chronic pain will cause opioids to decline for chronic pain. However, (3), (4), and (6) also reveal two unintended effects of regulations and guidelines:

\section{The income effects of regulations}

Firstly, in (3), regulations on acute pain opioids will increase opioids for chronic pain. This is due entirely to income effects $\left(\mathrm{U}_{11}\right)$. That is, when profits are pinched on acute pain opioids due to the regulations, physicians increase opioid volume for chronic pain in order to maintain a certain level of income. This behavior was first noted in general by McGuire and Pauly (1991) (albeit, in the context of volume increasing after reimbursement 
decreases). There is also an income effect on acute pain opioids in (4), where we see that the acute pain quantity of opioids will decrease with regulation $\mathrm{R}$ if the income effect $\mathrm{U}_{11}$ is small (close to 0). However, if the income effect is large, it can be the case that doctors actually increase the quantity of acute pain opioid prescriptions as regulation $\mathrm{R}$ increases. Overall, the empirical implication of these income effects is that physicians will increase new opioid starts or continuations (refills) for chronic pain patients, as well as possibly for acute pain patients, as state regulations become more severe on acute pain opioids.

\section{The spillover effects of guidelines}

As the perceived value of opioids declines for chronic pain patients due to the new information in the guidelines, the quantity of opioids for chronic pain declines in (5). This is the intended direct effect of guidelines on the management of chronic pain. However, guidelines also have a spillover effect on how physicians deal with acute pain, causing them to decrease opioids for acute pain as well, as seen in (6). Intuitively, the guidelines cause a direct decrease in chronic pain opioids due to the doctor learning that the chronic pain patient's benefits $\mathrm{V}_{\mathrm{c}}$ were less than expected. As a result, the doctor would prefer a compensating rise in $\mathrm{V}_{\mathrm{a}}$, (akin to the income effect of wanting to increase the profits on the unregulated drug). To accomplish this, the doctor surprisingly does not increase $q_{a}$. Recall that we are in an overprescribed state of the world where $\mathrm{q}_{\mathrm{a}}{ }^{*}$ is larger than $\mathrm{q}_{\mathrm{a}}$,', the optimum of $\mathrm{V}_{\mathrm{a}}$. Thus, to increase $\mathrm{V}_{\mathrm{a}}$, one has to decrease $\mathrm{q}_{\mathrm{a}}$ down from $\mathrm{q}_{\mathrm{a}}{ }^{*}$ towards $\mathrm{q}_{\mathrm{a}}$," This explains the spillover effect on acute pain opioids.

Comparing (3) and (5), we see that regulations increase chronic pain opioids, while guidelines decrease them, leaving the net effect, when both policy levers are applied, in doubt. In contrast, comparing (4) and (6), both regulations and guidelines will likely decrease opioids for acute pain, unless there is a large income effect. Moreover, if there is a large income effect and the inequality in (4) is positive, we have the unusual case in (3) and (4) where the regulations cause opioids to increase for both acute pain and chronic pain patients. Thus, the actual impact of regulations and guidelines on opioids for both chronic pain and acute pain is an open question that we will next examine empirically.

\section{Data and methods}

We will use nationally representative data to estimate the effect of state regulations and the CDC guidelines as predicted by the theory model. Moreover, if there are direct effects in terms of reduced opioid use, we will examine if this was accomplished with tapering of opioid doses and by shifting to non-opioids, as well as if opioid discontinuations resulted in harm in terms of increased work limitations due to more pain the year after stopping.

The data come from the 2013-2017 Medical Expenditure Panel Survey-Household Component (MEPS-HC), sponsored by AHRQ. The MEPS-HC is a 2-year rotating panel of households designed to yield nationally representative estimates of health care expenditures for the civilian, non-institutionalized population (Cohen, 2000). We use the twoyear longitudinal files for Panels 18-21, which enable national estimates of person-level changes in health care utilization across each two-year period. The pooled sample includes 48,509 adults; we exclude 1474 adults who do not have two years of data (3.0\%). We further exclude 2439 adults with cancer (5.1\%), leading to a final sample of 44,596 adults. 


\section{Chronic pain treatment}

We identify adults treated for conditions associated with chronic pain using the Weitzman Quality Institute algorithm based on ICD-9-CM condition codes (Tian et al., 2013). This algorithm was used with MEPS data in prior research to examine opioid use among adults treated for conditions associated with chronic pain (Bernard et al., 2019). The most commonly treated conditions associated with chronic pain are back problems (59\%), osteoarthritis and other non-traumatic joint disorders (21\%), and systemic lupus and connective tissues disorders (20\%). Starting in 2016, MEPS transitioned to ICD$10-\mathrm{CM}$ codes. There is no structural break in the chronic pain trend from 2014 to 2017 due to the transition to ICD-10, as shown in Appendix 1 Table 1. Our final sample includes 4982 adults with chronic pain treatment and 39,614 with no chronic pain treatment in the current year. We will refer to non-chronic pain as acute pain.

\section{Policy variables}

There are two key policy variables. The first is an indicator for the CDC Guidelines released in March 2016, which assigns a value of 1 for 2016 and 2017 and 0 for 2014 and 2015. The second is an indicator for state regulations, which assigns all observations in a given state a value of 1 for the year it is implemented and all subsequent years, and 0 for years before implementation. Appendix 1 Table 2 lists the state regulations. Thirteen states had a comprehensive Prescription Drug Monitoring Programs (PDMP) mandate, which met the criteria defined by Wen et al. (2019) Appendix 1 Table 2 (Wen et al., 2019). Eleven states had Pill Mill laws, which impose state oversight over pain clinics (Rutkow \& Vernick, 2017). Seventeen states had caps on the quantity of opioids, with fifteen limiting the first prescription to a seven-day supply.

\section{Empirical methods}

Policies can decrease opioid use either by decreasing the number of new starters or by decreasing the number of persisters, as examined below.

\section{Adults with acute pain}

(1) New starts (initiation) of prescription opioids using data from the second or "current" year of MEPS on opioid naive persons (i.e., those with no observed prescription opioid use in the first or "prior" year of MEPS), we examine the likelihood of three choices in the second year:

a. filling at least one opioid prescription,

b. use of a prescribed non-opioid analgesic-only, or

c. no prescribed opioids or non-opioids at all. 
(2) Persistence of prescription opioids among those who began prescription opioid use in the first half of the prior year (their first year in MEPS), we examine three choices:

a. the continued use of prescription opioids in the second year of MEPS,

b. discontinuing prescription opioids and using a prescribed non-opioid analgesic, or

c. discontinuing prescription opioids and using no prescribed non-opioids at all.

In both cases, we estimate multinomial logit regressions (See Appendix 1-Methods for details). Following AHRQ 2020 recommendations, we code non-opioid analgesics using the following drug therapeutic classes from the 2018 Redbook: nonsteroidal anti-inflammatory drugs (NSAIDs), muscle relaxants, anticonvulsants, corticosteroids, antidepressants, and antiarrhythmics (Ryder and Stannard 2005; AHRQ 2020a).

\section{Adults with chronic pain}

(1) New starts (initiation) of prescription opioids as in the case for those with acute pain, for opioid naive persons with chronic pain, we estimate a multinomial logit regression for the likelihood of the three choices: filling at least one opioid prescription in the second year, use of a prescribed non-opioid analgesic, or no prescribed analgesics at all.

(2) Persistence of prescription opioids as for adults without treatment for chronic pain, we examine data from the second or "current" year of MEPS for persons with prescribed opioid use in the first or "prior" year of MEPS. In this instance, however, we first examine all persons with chronic pain who had any year $1 \mathrm{use}$. We then focus more narrowly on "long term users" (those whose opioid use began prior to the start of MEPS). We use these samples to estimate multinomial logit regressions for the likelihood of the three choices: continued use of prescription opioids, discontinuing prescription opioids and either using a prescribed non-opioid analgesic or no prescribed analgesics at all.

(3) Tapering of prescription opioid use among long-term users here, we subset to chronic pain patients with prescription opioid use in both years of MEPS and whose use began prior to MEPS. For these long-term users, we measure tapering as the withinperson \%\%age drop in their number of annual opioid prescription fills between years 1 and 2. We also examine tapering as changes in the distribution of annual (cumulative) MME (Morphine Milligram Equivalents) across long-term users, using two annual MME categories: below 700, and above 3000. We first focus on $700 \mathrm{MME}$ since the $\mathrm{CDC}$ has determined that, for a new user, this is the critical point at which the probability of continuing opioids for one and three years has the largest incremental increase (Shah et al., 2017). The 3000 MME threshold approximately splits the remaining sample in half. For estimating the probability of using less than $700 \mathrm{MME}$ (or more than $3000 \mathrm{MME}$ ), we use logit regression analysis. For the effect on the within-person change in number of opioid fills from years 1 to 2 , we use linear regression analysis.

Finally, for both acute and chronic pain, we examine people who stopped opioids in year 1 to see if in year 2 they had worse, same, or less work limitations due to pain compared to year 1 . We estimate this change in limitations with a multinomial logit on three outcomes (less limitations, the same limitations, or more limitations) among those who took opioids in year 1 . The key independent variables are stopping opioids in year 1 interacted with state regulations and with the $\mathrm{CDC}$ guidelines. See Appendix 1 for method details. 
All models control for the following year 2 variables: time trend, age, age squared, sex, race/ethnicity, pain limitations in work, insurance status, priority chronic conditions, mental health status, hopelessness, surgery, obesity, pregnancy, smoking, marital status, employment, poverty, education, and rural. We also include state fixed effects. All results are weighted to represent the U.S. civilian non-institutionalized population. Descriptive statistics are reported in Appendix 2 Tables 3 and 4. All regression results are reported in Appendix 2. All analyses were conducted using svy commands in Stata 16, adjusting the standard errors for the complex survey design.

\section{Results}

From 2014 to 2017, on average there were 28.2 million adults with chronic pain in a given year, accounting for $12.2 \%$ of the civilian non-institutionalized population. From 2014 to 2017, for those without chronic pain, opioid use (as any use in the year) declined $23 \%$ from 10.2 to $7.9 \%$. Opioid use among those with chronic pain declined $14 \%$ from 39.9 to $34.0 \%$. And, among long-term (past multi-year) users with chronic pain, opioid use declined by $8 \%$ from 92.6 to $85.0 \%$ (Data Not Shown).

\section{Impact on opioids}

In Figs. 1 through 4, the right-hand side columns show the effect of guidelines and state regulations on opioid use.

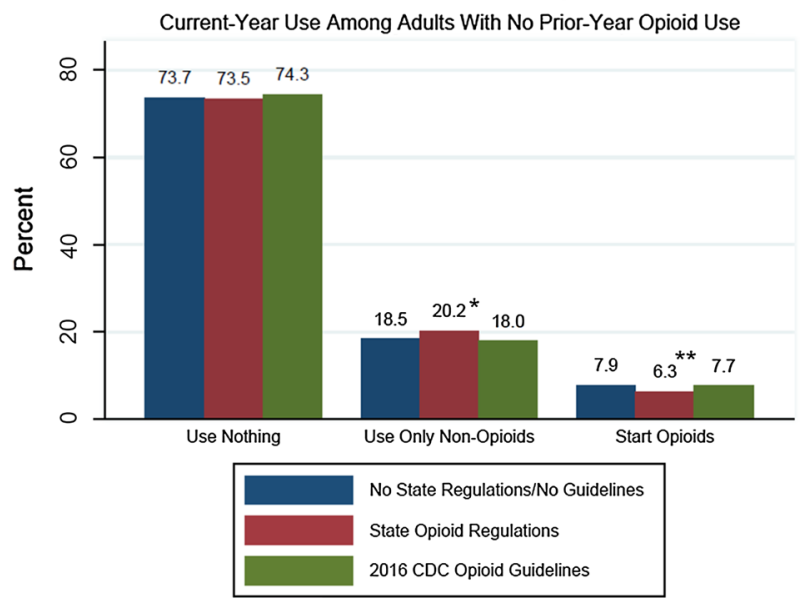

Fig. 1 The effects of state regulations and the CDC guidelines on starting opioids versus using only nonopioids among adults with acute pain, 2014-2017. Nationally representative estimates of the effects of the 2016 CDC guidelines and state regulations (caps on number of prescription, pill mill laws, and comprehensive PDMPs) on current year opioids use or non-opioids analgesics-only among adults with acute pain with no opioids in prior year, excluding cancer patients. See Appendix 2 Table 5 for full state-fixed multinomial regression. $* * *(* *)(*)$ statistically significant difference compared to the no state regulations/no guidelines case at the $p<0.01(p<0.05)(p<0.1)$ level. Sources: Authors' calculations using MEPS 


\section{Adults with acute pain}

Figure 1 shows that among adults with acute pain and without opioid use in the prior year, the state regulations (red bars) were associated with a $1.6 \%$ point decline (from 7.9 to $6.3 \%, p=0.03$ ) in the percentage of people starting new opioid use, compared to the counterfactual with neither CDC Guidelines nor state regulations (blue bars). These results are consistent with Sacks et al., (2019) who show that most of these state regulations limiting opioid use affected initial prescriptions. There was no statistically significant association between the CDC Guidelines and initiation of prescribed opioids for adults without chronic pain.

Figure 2 shows prescription opioid persistence among adults with acute pain who initiated opioid use during the first half of the prior year (their first year in MEPS). The CDC Guidelines (green bars) were associated with a $12.4 \%$ point reduction in the frequency of prescription opioid use in the second year of MEPS (from 28.6 to $16.2 \%$, $p=0.001$ ).

Overall, Fig. 2 corroborates our theory section result on the spillover effect in (6) the CDC guidelines on chronic pain spilled over to reduce opioids for acute pain by increasing discontinuations $(p<0.01)$. Moreover, Fig. 2 demonstrates the dominating of the income effect in (4) as discussed in the theory section. In particular, the state regulations were associated with a $32 \%$ increase in opioid continuations from 28.6 to $37.8 \%$ for acute pain $(p=0.09)$.

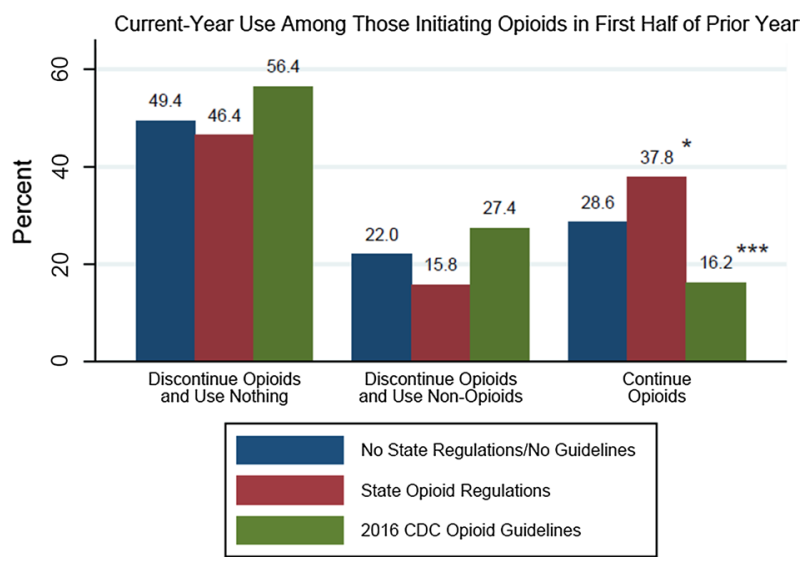

Fig. 2 The effects of state regulations and the CDC guidelines on discountinuing opioids and using nonopioids analgesics after starting opioids among adults with acute pain, 2014-2017. Nationally representative estimates of the effects of the 2016 CDC guidelines and state regulations (caps on number of prescription, pill mill laws, and comprehensive PDMPs) on the percent of prior year opioids users (starting in first half of the prior year) who discontinue opioids in the current year with nothing else used, or with non-opioids analgesics only, or continue with opioids, for those with acute pain, excluding cancer patients. See full state fixed effect multinomial logit regression result in Appendix 2 Table 7. *** (**) (*) statistically significant difference compared to the no state regulations/no guidelines case at the $p<0.01(p<0.05)(p<0.1)$ level. Sources: Authors' calculations using MEPS 


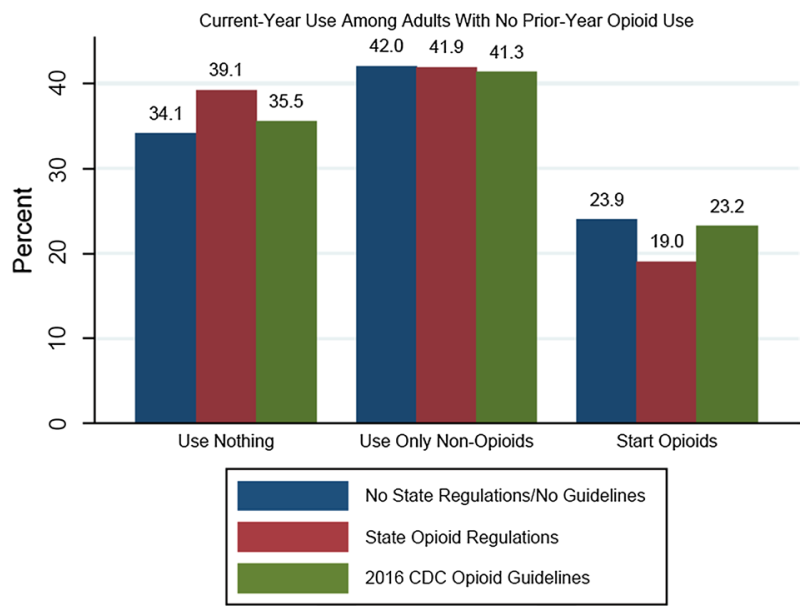

Fig. 3 The effects of state regulations and the CDC guidelines on starting opioids versus using only nonopioids among adults with chronic pain, 2014-2017. Nationally representative estimates of the effects of the 2016 CDC guidelines and state regulations (caps on number of prescription, pill mill laws, and comprehensive PDMPs) on current year opioids use or non-opioids analgesics-only among adults with chronic acute pain with no opioids in prior year, excluding cancer patients. See Appendix 2 Table 5 for full statefixed multinomial regression. $* * *(* *)(*)$ statistically significant difference compared to the no state regulations/no guidelines case at the $p<0.01(p<0.05)(p<0.1)$ level. Sources: Authors' calculations using MEPS

\section{Adults with chronic pain}

Similar to the case for adults without chronic pain, Fig. 3 suggests that state regulations may have been associated with a $4.9 \%$ point decline in new starts among adults with chronic pain, although these results were not significant $(p=0.14)$. As was also the case for adults without chronic pain, the CDC Guidelines did not appear to affect new starts for this group.

The CDC Guidelines were associated with large declines in the rate of prescription opioid persistence. Figure 4 shows that among adults with chronic pain who had opioid use in the prior year, the CDC Guidelines were associated with an $11.4 \%$ point decline in the percent continuing with opioids into the current year (from 74.3 to $62.9 \%, p=0.07$ ), compared to the counterfactual with neither CDC Guidelines nor state regulations. Finally, in Fig. 4, we do see partial evidence of the income effect predicted in (3) in the theory section: an increase of $3.3 \%$ points for continuations for chronic pain due to state regulations, but the latter effect is not statistically significant $(p=0.45)$.

\section{Impact on non-opioids}

\section{Adults without chronic pain}

In Fig. 1, the $1.6 \%$ point decline (from 7.9 to $6.3 \%, p=0.03$ ) in the percentage of people starting new opioid use was accompanied by a $1.7 \%$ point increase (from 18.5 to $20.2 \%, p=0.07$ ) in those taking non-opioid analgesics instead of starting opioids. In Fig. 2, a little more than 


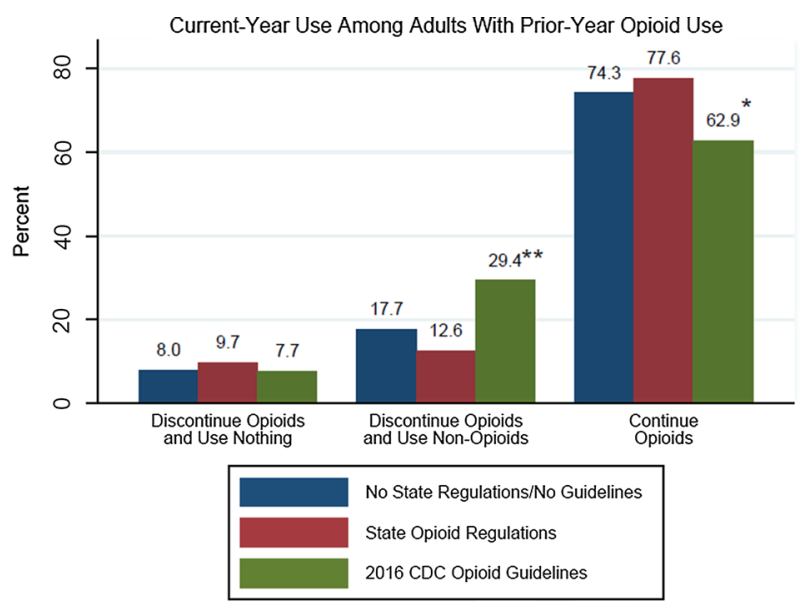

Fig. 4 The effects of state regulations and the CDC guidelines on discountnuing opioids and using nonopioids analgesics among adults with chronic acute pain, 2014-2017. Nationally representative estimates of the effects of the 2016 CDC guidelines and state regulations (caps on number of prescription, pill mill laws, and comprehensive PDMPs) on the percent of prior-year opioids users discontinue opioids in the current year with nothing else used, or with non-opioids analgesics only, or continue with opioids, for those with chronic pain, excluding cancer patients. See full state fixed effect multinomial logit regression result in Appendix 2 Table 7. *** (**) (*) statistically significant difference compared to the no state regulations/no guidelines case at the $p<0.01(p<0.05)(p<0.1)$ level. Sources: Authors' calculations using MEPS

half of the $12.4 \%$ point reduction in persistence was due to an increase (from 49.4 to $56.4 \%$ ) in adults who discontinued opioids and used no prescription pain relievers at all, with the remainder reflecting an increase (from 22.0 to 27.4\%) in adults who used non-opioid analgesics instead of opioids. In terms of relative risk ratios, adults without chronic pain under CDC Guidelines had 186\% ( $p=0.02)$ higher relative risks of taking a non-opioid-only over continuing opioids compared to if there were no CDC Guidelines (not shown). However, this group likely did not substitute non-opioid analgesics for opioids since they maintained a constant number of non-opioid prescription fills (6.6) per year in years 1 and 2 (not shown).

\section{Adults with chronic pain}

In Fig. 3, offsetting the $4.9 \%$ point decline in new starts was a 5\% point increase in the use of no pain medications, although again this was not statistically significant $(p=0.15)$. In terms of relative risk ratios, adults with chronic pain under state regulations had $37.2 \%$ $(p=0.08)$ lower relative risks of choosing a new start over no analgesics compared to if there were no state regulations (not shown). As was also the case for adults without chronic pain, the CDC Guidelines did not appear to affect new starts for this group.

In Fig. 4, in addition to the CDC Guidelines being associated with an $11.4 \%$ point decline in the percent continuing with opioids (from 74.3 to $62.9 \%, p=0.07$ ), the Guidelines were also associated with an $11.7 \%$ point increase in the use of non-opioid analgesics (without opioids) (from 17.7 to $29.4 \%, p=0.03$ ). This was a $66.1 \%$ increase in non-opioid-only analgesics use after prior-year opioid use. Among these non-opioid users, there was an increase in the annual number of non-opioid fills of 1.5 from 8.1 to 9.6 between years 1 and 2 (not shown) $(p<0.01)$. Thus, the opioid discontinuations may partially substitute into non-opioids. 
The sample for Fig. 4 includes adults with chronic pain who had prior year prescription opioid use. To further examine opioid use patterns for long-term users, we subset to those with prescription opioid starts that predated their MEPS participation. Our estimates for continuing opioids versus switching to only non-opioid analgesics yield results for longterm users that are stronger than those in Fig. 4. In particular, while the CDC Guidelines were again associated with increased discontinuation $(p=0.081)$ and substitution into nonopioid analgesics $(p=0.047)$, less than one percent of long-term users discontinue opioids and go without any prescribed pain relief (not shown). For this long-term user group, there was a 131.4 percent increase (from 8.6 to $19.9 \%$ ) in non-opioid-only analgesic use associated with the CDC Guidelines [an effect that was twice as large as the $66 \%$ increase for all users (Fig. 4)]. Moreover, long-term users increased their number of annual non-opioid analgesic fills by 1.3 from 11.9 to 13.2 ( $p<0.001$ ) between years 1 and 2 (not shown).

\section{Impact on non-stoppers: tapering}

Nevertheless, most long-term users continued opioids into the current year. For this subset of adults, representing on average $17.4 \%$ of all those with chronic pain, the CDC Guidelines were associated with increased tapering of the number of opioid fills between the prior and current years (results are summarized below, not shown in tables). Under the CDC Guidelines, a majority of these long-term users (53.9\%) tapered fills, compared to 34.8 percent if there were neither CDC Guidelines nor state regulations $(p=0.023)$. On average, the CDC Guidelines were associated with a drop of two opioid prescriptions between years 1 and 2, within-person, from 9.6 to 7.6 prescriptions annually ( $p=0.083$ ). The share of long-term users with chronic pain using less than 700 annual MMEs increased from 14.4 to 26.2 percent under the CDC Guidelines, compared to no Guidelines and no state regulations $(p=0.076)$. The CDC Guidelines were associated with only a small decline in the share of long-term users with chronic pain using more than 3000 annual MMEs, from 55.9 to $53.8 \%$ (a difference that is not statistically significant). Overall, state regulations had no impact on tapering among long-term users with chronic pain. An open question is whether tapering was also associated with substitution toward non-opioid analgesics. We cannot accurately measure this concurrent use of non-opioids and opioids since many opioid pills already come combined with a non-opioid analgesic.

\section{Impact on stoppers: work limitations due to pain}

For patients who discontinued opioids, it may be the case that the guidelines and state regulations caused patients to stop opioids "too early." In Figs. 5 and 6, we try to measure this by examining whether their work limitations due to pain actually increased the year after they stopped opioids (relative to limitations in the prior year). Work limitations refer to pain interfering with normal work, ranging from 1 (not at all) to 5 (extremely). In Fig. 5, for acute pain, we see that in the year after stopping opioid, work limitations were not exacerbated by stopping opioids under regulations or guidelines compared to the counterfactual of no guidelines or regulations. However, in Fig. 6, for people with chronic pain, the stopping attributable to the guidelines was associated with fewer people having a decline or no change in work limitations in the following year (relative to the prior year) compared to the counterfactual of no guidelines and no regulations. Work limitations did increase for $24.8 \%$ of them, but this was not statistically significant different from the $17.3 \%$ under the counterfactual. In contrast, the stopping attributable to the state regulations was associated 


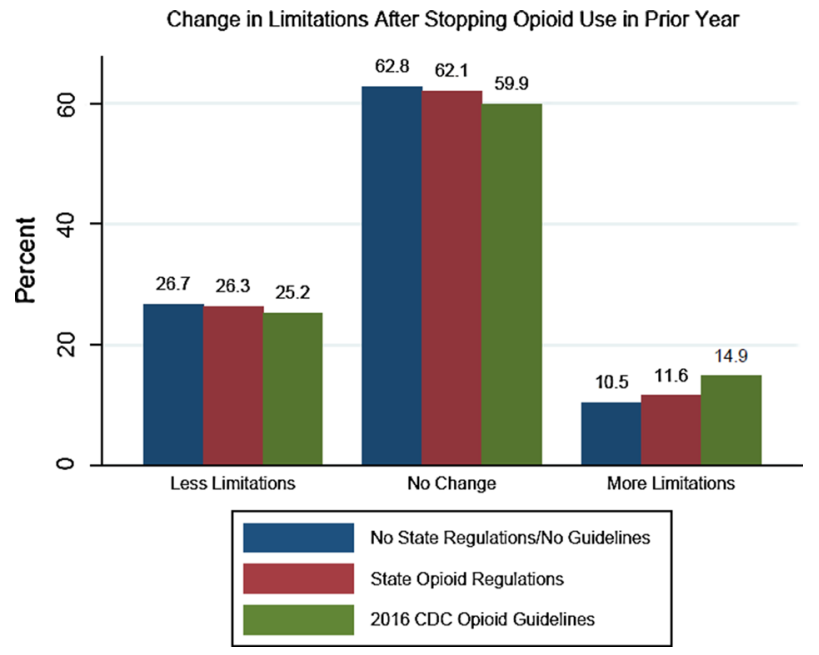

Fig. 5 Work limitation due to pain after discontinuing opioids under state regulations and the CDC guidelines among adults with acute pain, 2014-2017. Nationally representative estimates of the effects of the 2016 CDC guidelines and state regulations (caps on number of prescription, pill mill laws, and comprehensive PDMPs) on the change in work limitation due to pain from year 1 to 2 year among adults with acute pain and opioid use in prior year, excluding cancer patients. Stopping is interacted with guidelines and regulations. See Appendix 2 Table 13 for full state-fixed multinomial regression. *** (**) (*) statistically significant difference compared to the no state regulations/no guidelines case at the $p<0.01(p<0.05)$ $(p<0.1)$ level. Sources: Authors' calculations using MEPS

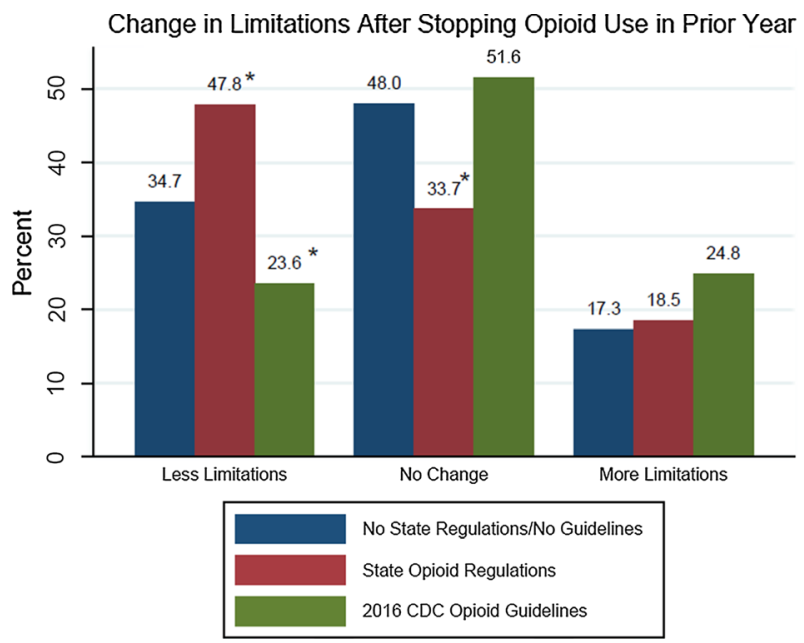

Fig. 6 Work limitation due to pain after discontinuing opioids under state regulations and the CDC guidelines among adults with chronic pain, 2014-2017. Nationally representative estimates of the effects of the 2016 CDC guidelines and state regulations (caps on number of prescription, pill mill laws, and comprehensive PDMPs) on the change in work limitation due to pain from year 1 to year 2 among adults with chronic pain and opioid use in prior year, excluding cancer patients. Stopping is interacted with guidelines and regulations. See Appendix 2 Table 13 for full state-fixed multinomial regression. *** (**) (*) statistically significant difference compared to the no state regulations/no guidelines case at the $p<0.01(p<0.05)$ $(p<0.1)$ level. Sources: Authors' calculations using MEPS 
with a large drop in work limitations the following year, with $47.8 \%$ of stoppers under state regulations versus $34.7 \%$ of stoppers in the counterfactual experiencing less limitation due to pain. This may be a manifestation of the income effect in (3) in our theory section that was corroborated by the data, where we saw that physicians react to state regulations by decreasing new starts on acute pain and increasing continuations on chronic pain patients. If this is indeed happening, then the chronic pain patients that these doctors select to continue with opioids are likely the sicker patients, and those that discontinue in this scenario may be healthier than average. Thus, we observe decreased work limitations the year after for these "selection-biased" stoppers. Overall, we have a mixed picture for patients with chronic pain. We cannot say that the guidelines and regulations significantly harmed stoppers by stopping them too early, but clearly this should be studied in future research.

\section{Discussion}

Our research lies at the intersection of two growing literatures. One line of research employs cohort studies to examine the dynamics of opioid use, using either household survey data or clinical samples of convenience (Alghnam \& Castillo, 2017; Heins et al., 2016; Hoppe et al., 2015). The other examines the determinants and consequences of the public interventions that reduced aggregate prescription opioid use (Adams \& Giroir, 2019; Schieber et al., 2019; Olaughlin et al., 2018; Bernard et al., 2019; Haffajee et al 2018; Bao et al., 2018; Wen et al, 2017; Hincapie-Castillo et al., 2020). Ours is the first study to examine how public interventions at the federal and state levels may have affected the dynamics of opioid use. Of particular importance, we stratify our analysis based on the presence or absence of (non-cancer) chronic pain. Our research yields 6 main findings:

(1) Direct effects. State regulations were associated with decreased prescribed opioid initiation for adults without chronic pain. The CDC Guidelines were associated with reduced persistence of prescribed opioid use for adults with chronic pain.

(2) Income effects. State regulations were associated with increased prescribed opioid continuations for adults with and without chronic pain, corroborating the presence of physician income effects as predicted by the theory.

(3) Spillover effects. The CDC Guidelines were associated with reduced persistence of prescribed opioid use for adults with acute pain, corroborating the spillover effect of guidelines predicted by the theory.

(4) Non-opioid substitution. The CDC Guidelines were associated with a corresponding increase in non-opioid-only analgesic use among opioid-discontinuing adults, with some degree of non-opioid substitution for those with chronic pain.

(5) Tapering. Among long-term opioid users with chronic pain who continued to use prescription opioids, the CDC Guidelines were associated with a tapering in the number of annual opioid prescription fills and with a shift towards lower annual MME.

(6) Harm. People attributed to stopping opioids due to the CDC guidelines were more likely to have elevated, but statistically insignificant work limitations due to pain a year after stopping (compared to the year before). People attributed to stopping opioids due to state regulations were more likely to have less pain limitations than the year before stopping compared to stoppers under no state regulations and before the CDC guidelines. 
Taken together, these results indicate that the guidelines and regulations did work as predicted by theory, both in terms of anticipated outcomes and in terms of unintended effects, both good and bad. However, these incentives were displayed in unexpected ways. The bulk of the incentives were manifested in terms of opioid continuations or discontinuations. The only incentive working through initial starts were state regulations and their direct impact on acute pain starts. Future research should examines why this is the case.

One limitation of our research is that while the MEPS contains detailed information on prescribed medicines, it does not ask questions regarding illicit use. If discontinuation or tapering among long-term users of prescription opioids was associated with increased illicit use, that would be an unfavorable outcome that is not measured in MEPS. Another limitation is that while MEPS supports analysis of year-to-year changes in opioid use, it is not really designed to capture within-year, month-to-month variation in use that would help to determine whether discontinuations between the two years of MEPS were managed with an appropriate degree of tapering. As noted in our Introduction, important concerns were raised about abrupt discontinuations for persons with chronic pain, and in some cases opioid dependencies, due to the federal and state interventions to alter opioid prescribing during our study period. In response, HHS in 2019 released a new guide for clinicians on appropriate dosage reduction and discontinuation of long-term opioid analgesics for persons with chronic pain. In 2020, AHRQ released the Six Building Blocks Program for improving the care of long-term opioid users, including a self-service how-to guide for clinicians (AHRQ 2020b). Future research using more detailed claims data may prove helpful in tracking the impact of policy interventions on the within-year dynamics of opioid prescribing.

Our results on the CDC Guidelines give much hope that long-term chronic pain opioid users can be successfully shifted off opioids and onto non-opioid analgesics. However, the CDC Guidelines were not successful at reducing new starts of opioids among naïve users. Instead, state regulations had success with reducing new opioid starts among people without chronic pain, while encouraging new starts with non-opioid analgesics, and without adversely impacting long term chronic pain opioid users. Many of these state regulations such as limits on number of pills did not apply to people with chronic pain. Our results indicate that it may be useful to begin to apply these state regulations to people with chronic pain in order to reduce new opioid starts.

\section{Appendix 1: Methods}

\section{Background on the Medical Expenditure Panel Survey Household Component (MEPS-HC)}

Data are household reported and one respondent typically reports for the entire household. A computer assisted personal interviewing (CAPI) data collection mode is used and questions are asked for a recall period of about 3-6 months.

\section{Medical conditions}

Medical conditions in the MEPS-HC were collected from households verbatim and coded by professional coders using the International Classification of Diseases, Ninth Revision (ICD-9). 
Chronic conditions are defined using the fully specified ICD-9-CM diagnosis codes. The MEPS medical condition files include conditions associated with medical events, disability days and/ or days reported as bothersome due to a health issue during the year. The MEPS event types for which associated condition information is collected include office-based medical visits, hospital outpatient department visits, visits to emergency departments, hospital inpatient stays, prescribed medicines fills, and home healthcare. Associated health condition information is not collected in MEPS for dental visits or other miscellaneous healthcare expenditures.

\section{Prescription drugs}

Only prescribed drugs purchased in outpatient settings are included in MEPS; because it is a household survey, information on prescription medicines administered in an inpatient setting or in a clinic or physician's office are not collected. We examine outpatient prescription fills of opioids that are commonly used to treat pain. These opioids are identified using generic drug names for narcotic analgesics and narcotic analgesic combinations in the Multum Lexicon database from Cerner Multum, Inc. We excluded opioids not used for pain management from this analysis. These exclusions, which encompass respiratory agents, antitussives, and drugs commonly used in Medication Assisted Treatment, comprise about 8.5\% of opioid fills reported in MEPS. MEPS-HC collects for each prescription, the drug name, the number of times it was obtained, the health condition it was prescribed for, outof-pocket payment amount and the usual third-party payer (see Hill et al., 2014). Because the MEPS-HC is a household survey, the data collected are self-reported.

However, MEPS also includes a Medical Provider Component (MPC) that collects data from hospitals, physicians, home health care providers, and pharmacies identified by MEPS-HC respondents on both the medical and financial characteristics of medical events. Its purpose is to supplement and/or replace expenditure information received from the MEPS-HC respondents about the health care that was provided to household members in the course of the survey year. For survey respondents who sign permission forms authorizing MEPS to contact their pharmacies and authorizing their pharmacies to release records to MEPS, the Pharmacy Component (PC) contacts the pharmacies identified by $\mathrm{HC}$ respondents, and collects for each acquisition of a drug, the date the prescription was filled or refilled, the National Drug Code, the quantity dispensed, the number of days supplied and the amount of out-of-pocket and third party payments.

\section{Chronic pain}

We identify adults treated for conditions associated with chronic pain using the Weitzman Quality Institute algorithm based on ICD-9-CM condition codes (See Tian et al., (2013)). We use the ICD-9-CM listed in Bernard et al., (2019), updated to ICD-10-CM, to define chronic pain. Unlike claims data, MEPS' advantage is that it relies not just on conditions reported during medical visits, but it also ascertains the patient's reason (condition) for obtaining the medication. MEPS also provides a measure, from the Medical Outcomes Study 36-Item Short-Form Health Survey (SF-36), of how pain interfered with work during the prior four weeks. This pain measure is not appropriate for this analysis because adults with chronic pain cannot be identified based on pain interference (see Olfson et al., 2020)

In Table 1 below, we verify that the shift from ICD-9 to ICD-10 to define chronic pain did not cause a structural break in our data. 
Table 1 Testing for break in chronic pain trend 2014-2017 due to transition to ICD-10 in 2016

\begin{tabular}{lll}
\hline Variables & $\begin{array}{l}\text { Probability of Chronic Pain } \\
\text { (No covariates) }\end{array}$ & $\begin{array}{l}\text { Probability of Chronic Pain } \\
\text { (All covariates) }\end{array}$ \\
\hline Trend & 0.00568 & -0.00033 \\
& $(0.006)$ & $(0.005)$ \\
ICD-10 & -0.00372 & -0.01470 \\
& $(0.022)$ & $(0.021)$ \\
Trend* & -0.00759 & -0.00010 \\
ICD-10 & $(0.008)$ & $(0.007)$ \\
Observations & 44,596 & 44,596 \\
\hline
\end{tabular}

Logit estimate of patient having any chronic pain during their two years in the data. Marginal effects reported. Standard errors in parentheses adjusted for complex survey design. Covariates are all the patient covariates of Appendix 2 Table 5 except for the two policy variables

$* * * p<0.01 ; * * p<0.05 ; * p<0.1$

\section{Regressions}

All regressions (other than for Figs. 5 and 6) come in pairs of the form:

$$
\begin{gathered}
Y_{i t}=f\left(b 1 * C D C_{t}+b 2 * \text { StateRegulation }_{s t}+b 3 * \text { trend }_{t}+b 4 * X_{i t}+b_{s}+e_{i t}\right) \\
\text { ifchronicpain }=0, \\
Y_{i t}=f\left(b 1 * C D C_{t}+b 2 * \text { StateRegulation }_{s t}+b 3 * \text { trend }_{t}+b 4 * X_{i t}+b_{s}+e_{i t}\right) \\
\text { ifchronicpain }=1,
\end{gathered}
$$

where $\mathrm{i}$ is the individual, $\mathrm{s}$ is State, and $\mathrm{t}$ is time, $\mathrm{Y}$ is the outcome, e is an error term, CDC is the 0/1 dummy for the CDC Guideline period 2016-2017, StateReform are 0/1 dummies flagging any one of the Regulations of Table 2, $\mathrm{X}$ are patient covariates from year 2 , and $b_{s}$ are State fixed effects. The functional form $f(*)$ is multinomial logit when $Y$ represents three outcomes (opioid use, non-opioid use, no use), logit when Y is binary, and linear when $\mathrm{Y}$ is the change in number of opioid prescriptions from years 1 to 2 .

Regressions for Figs. 5 and 6 (work limitations due to pain after stopping opioids) are on the subsample of those who used opioids in year 1, and are in the form:

$$
\begin{aligned}
& Y_{i t}=f\left(\begin{array}{c}
b 0 * \text { stop }+b 1 * C D C_{t}+b 2 * \text { StateRegulation }_{s t}+b 3 * \text { stop } * C D C_{t}+ \\
b 4 * \text { stop } * \text { StateRegulation }_{\text {st }}+b 5 * \text { trend }_{t}+b 6 * X_{i t}+b_{s}+e_{i t}
\end{array}\right) \\
& \text { ifchronicpain }=0 \text {, } \\
& Y_{i t}=f\left(\begin{array}{c}
b 0 * \text { stop }+b 1 * C D C_{t}+b 2 * \text { StateRegulation }_{s t}+b 3 * \text { stop } * C D C_{t}+ \\
b 4 * \text { stop } * \text { StateRegulation }_{s t}+b 5 * \text { trend }_{t}+b 6 * X_{i t}+b_{s}+e_{i t}
\end{array}\right)
\end{aligned}
$$

ifchronicpain $=1$, 
where stop $=0,1$, indicates if the patient stopped taking opioids in year 1 with none in year 2. The functional form $\mathrm{f}(*)$ is multinomial logit, and Y represents three outcomes (less limitation, same limitation, worse limitation), comparing the change in work limitations due to pain between year 1 and year 2. Limitations range from not at all, a little bit, moderately, quite a bit, to extremely.

\section{State regulations}

See Table 2.

Table 2 State regulations at any time during 2014-2017 Sources: Limits: National Conference of State Legislatures (2019); Pill Mill laws: Rutkow and Vernick (2017); comprehensive PDMPs: Wen et al (2019), defined as, "All providers... are subject to the mandate; providers are required to check the program upon initial prescribing and at least every twelve months...; and providers are not allowed to rely on their own judgment to determine whether it is necessary to check the program in individual cases"

\begin{tabular}{|c|c|c|c|}
\hline State & $\begin{array}{l}\text { Limits on quanti- } \\
\text { ties }\end{array}$ & Pill Mill laws & $\begin{array}{l}\text { Compre- } \\
\text { hensive } \\
\text { PDMPs }\end{array}$ \\
\hline
\end{tabular}

AK $\quad \mathrm{x}$

AL

$\mathrm{X}$

AZ

$\mathrm{X}$

CA

$\mathrm{X}$

$\mathrm{X}$

FL $x$

GA $\quad x$

HI $\quad \mathrm{x}$

IN $\quad x$

KY $\quad \mathrm{x} \quad \mathrm{x} \quad \mathrm{x}$

LA $\mathrm{X}$

MA $\mathrm{x}$

MD $\mathrm{x}$

ME $\mathrm{X}$

MN $\mathrm{X}$

MS

$\mathrm{NC} \quad \mathrm{x}$

$\mathrm{NH} \quad \mathrm{x}$

NJ $\quad x$

NM $x$

NV $\quad x$

NY $\quad \mathrm{x}$

$\mathrm{OH} \quad \mathrm{x}$

PA $\quad x$

RI $\quad x$

TN $x$

TX $x$

UT $\quad \mathrm{X}$

WI $\quad x$

WV $\quad x$ 


\section{Appendix 2: Empirical results}

See Fig. 7, Tables 3, 4, 5, 6, 7, 8, 9, 10, 11, 12 and 13.

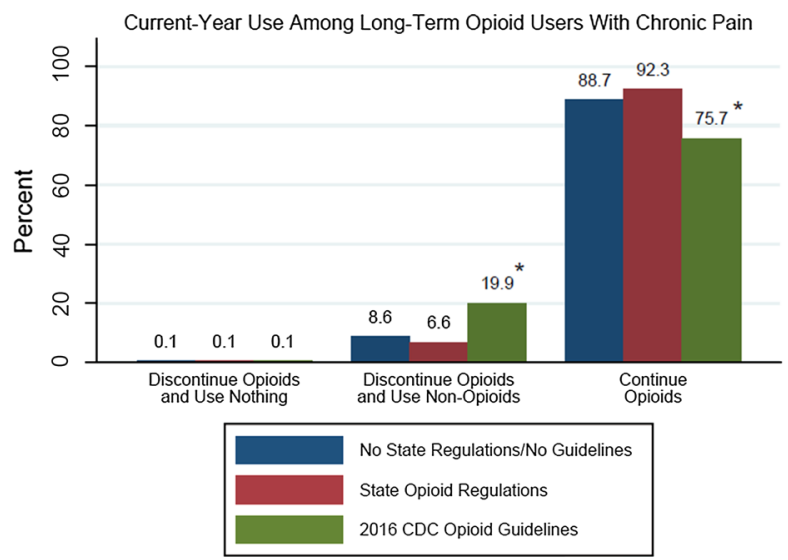

Fig. 7 The effects of state regulations and the CDC guidelines on discontinuing opioids and using nonopioids analgesics among long term opioids users with chronic pain, 2014-2017. Note that less than $0.1 \%$ discontinue with nothing used, so that option is not estimated. Thus, we report nationally representative logit estimates of the effects of the 2016 CDC guidelines and state regulations (caps on number of prescription, pill mill laws, and comprehensive PDMPs) on percent year of long term opioids users discontinuing opioids with non-opioids analgesics versus continuing with opioids, for those with chronic pain, excluding cancer patients and with long-term opioid use for two or more years. See full state fixed effect logit regression results in Appendix 2 Table 10.*** (**) $(*)$ statistically significant difference compared to the no state regulations/no guidelines case at the $p<0.01(p<0.05)(p<0.1)$ level. Sources: Authors' calculations using MEPS 


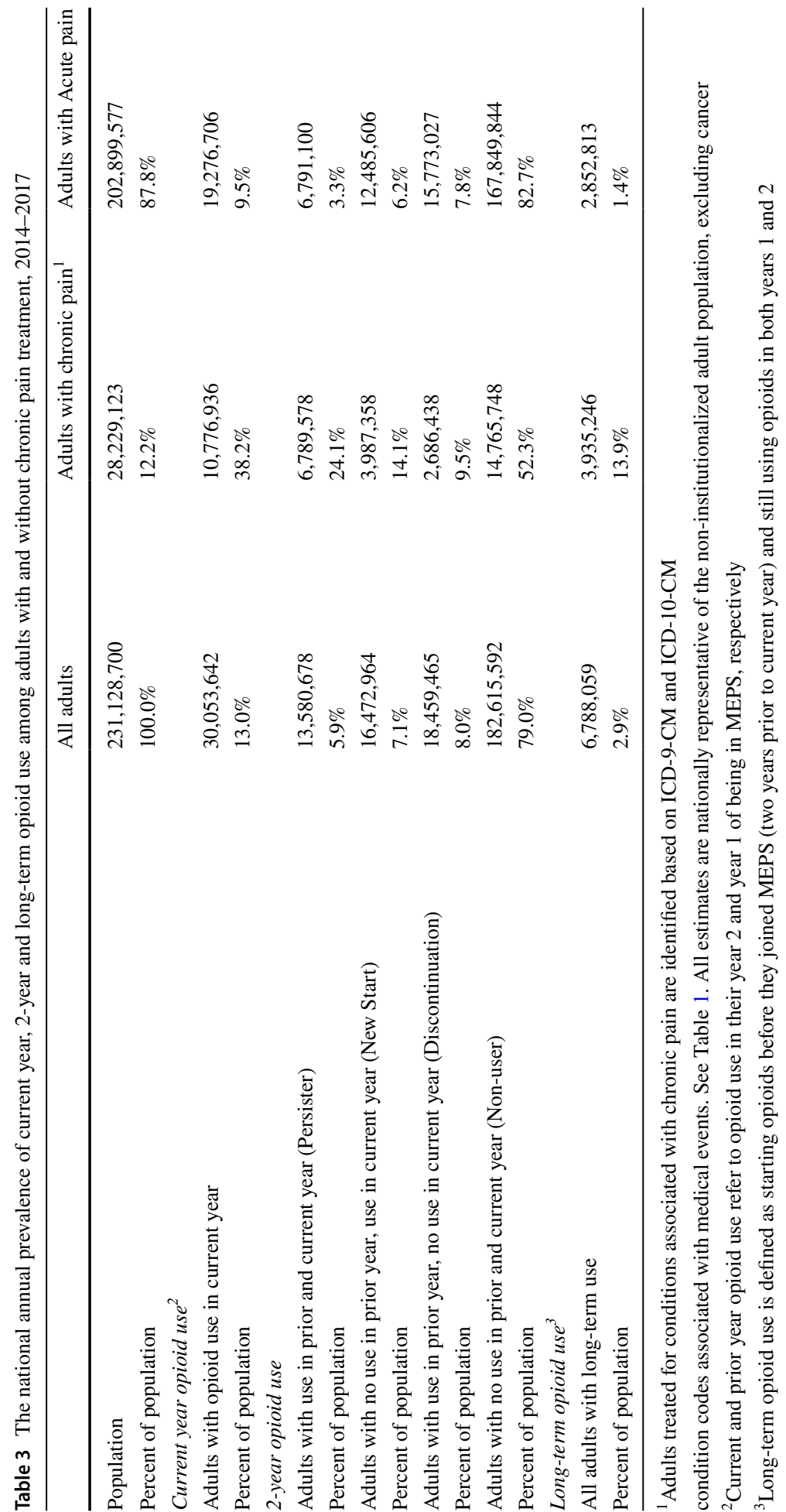


Table 4 Sample descriptive statistics, 2014-2017

\begin{tabular}{|c|c|c|}
\hline Variables & $\begin{array}{l}\text { (1) } \\
\text { Chronic pain }\end{array}$ & $\begin{array}{l}\text { (2) } \\
\text { Acute pain }\end{array}$ \\
\hline Opioid use & $\begin{array}{l}0.38 \\
(0.010)\end{array}$ & $\begin{array}{l}0.10 * * * \\
(0.002)\end{array}$ \\
\hline Opioid fills, prior year & $\begin{array}{l}1.84 \\
(0.078)\end{array}$ & $\begin{array}{l}0.28^{* * *} \\
(0.012)\end{array}$ \\
\hline Opioid fills, current year & $\begin{array}{l}2.05 \\
(0.079)\end{array}$ & $\begin{array}{l}0.26 * * * \\
(0.010)\end{array}$ \\
\hline Schedule II opioid use & $\begin{array}{l}0.30 \\
(0.010)\end{array}$ & $\begin{array}{l}0.07 * * * \\
(0.002)\end{array}$ \\
\hline MME if use, prior year & $\begin{array}{l}6,089 \\
(467)\end{array}$ & $\begin{array}{l}1,666 * * * \\
(130)\end{array}$ \\
\hline MME if use, current year & $\begin{array}{l}5,476 \\
(381)\end{array}$ & $\begin{array}{l}1,733 * * * \\
(121)\end{array}$ \\
\hline Non-opioid use only & $\begin{array}{l}0.34 \\
(0.009)\end{array}$ & $\begin{array}{l}0.19 * * * \\
(0.004)\end{array}$ \\
\hline CDC guideline & $\begin{array}{l}0.46 \\
(0.010)\end{array}$ & $\begin{array}{l}0.51 * * * \\
(0.004)\end{array}$ \\
\hline State regulations & $\begin{array}{l}0.46 \\
(0.018)\end{array}$ & $\begin{array}{l}0.53 * * * \\
(0.012)\end{array}$ \\
\hline Age & $\begin{array}{l}53.50 \\
(0.384)\end{array}$ & $\begin{array}{l}44.99 * * * \\
(0.195)\end{array}$ \\
\hline Male & $\begin{array}{l}0.42 \\
(0.008)\end{array}$ & $\begin{array}{l}0.49 * * * \\
(0.003)\end{array}$ \\
\hline Black & $\begin{array}{l}0.10 \\
(0.006)\end{array}$ & $\begin{array}{l}0.13 * * * \\
(0.007)\end{array}$ \\
\hline Hispanic & $\begin{array}{l}0.11 \\
(0.007)\end{array}$ & $\begin{array}{l}0.17 * * * \\
(0.009)\end{array}$ \\
\hline Surgery & $\begin{array}{l}0.07 \\
(0.004)\end{array}$ & $\begin{array}{l}0.03 * * * \\
(0.001)\end{array}$ \\
\hline Married & $\begin{array}{l}0.57 \\
(0.010)\end{array}$ & $\begin{array}{l}0.51 * * * \\
(0.005)\end{array}$ \\
\hline No college & $\begin{array}{l}0.39 \\
(0.011)\end{array}$ & $\begin{array}{l}0.43^{* * * *} \\
(0.006)\end{array}$ \\
\hline $1-3$ years college & $\begin{array}{l}0.30 \\
(0.008)\end{array}$ & $\begin{array}{l}0.28 * * \\
(0.004)\end{array}$ \\
\hline $4+$ years college & $\begin{array}{l}0.32 \\
(0.012)\end{array}$ & $\begin{array}{l}0.29 * * \\
(0.006)\end{array}$ \\
\hline Employed & $\begin{array}{l}0.59 \\
(0.010)\end{array}$ & $\begin{array}{l}0.72 * * * \\
(0.005)\end{array}$ \\
\hline Privately insured, nonelderly & $\begin{array}{l}0.53 \\
(0.011)\end{array}$ & $\begin{array}{l}0.61 * * * \\
(0.007)\end{array}$ \\
\hline Publicly insured, nonelderly & $\begin{array}{l}0.15 \\
(0.007)\end{array}$ & $\begin{array}{l}0.12 * * * \\
(0.004)\end{array}$ \\
\hline Elderly, Medicare & $\begin{array}{l}0.27 \\
(0.010)\end{array}$ & $\begin{array}{l}0.16^{* * * *} \\
(0.004)\end{array}$ \\
\hline Uninsured, nonelderly & $\begin{array}{l}0.04 \\
(0.004)\end{array}$ & $\begin{array}{l}0.11^{* * *} \\
(0.004)\end{array}$ \\
\hline Dual/SSI nonelderly & $\begin{array}{l}0.05 \\
(0.003)\end{array}$ & $\begin{array}{l}0.02 * * * \\
(0.001)\end{array}$ \\
\hline HMO & $\begin{array}{l}0.34 \\
(0.012)\end{array}$ & $\begin{array}{l}0.30^{* * * *} \\
(0.006)\end{array}$ \\
\hline
\end{tabular}


Table 4 (continued)

\begin{tabular}{|c|c|c|}
\hline Variables & $\begin{array}{l}\text { (1) } \\
\text { Chronic pain }\end{array}$ & $\begin{array}{l}\text { (2) } \\
\text { Acute pain }\end{array}$ \\
\hline Poor & $\begin{array}{l}0.13 \\
(0.005)\end{array}$ & $\begin{array}{l}0.12 * \\
(0.004)\end{array}$ \\
\hline Near poor & $\begin{array}{l}0.04 \\
(0.003)\end{array}$ & $\begin{array}{l}0.04 \\
(0.002)\end{array}$ \\
\hline Low income & $\begin{array}{l}0.12 \\
(0.006)\end{array}$ & $\begin{array}{l}0.13 \\
(0.003)\end{array}$ \\
\hline Middle income & $\begin{array}{l}0.25 \\
(0.008)\end{array}$ & $\begin{array}{l}0.29 * * * \\
(0.004)\end{array}$ \\
\hline High income & $\begin{array}{l}0.45 \\
(0.010)\end{array}$ & $\begin{array}{l}0.42 * * * \\
(0.007)\end{array}$ \\
\hline Rural & $\begin{array}{l}0.05 \\
(0.009)\end{array}$ & $\begin{array}{l}0.05 * * * \\
(0.007)\end{array}$ \\
\hline Pain limits work, last month & $\begin{array}{l}0.25 \\
(0.009)\end{array}$ & $\begin{array}{l}0.06 * * * \\
(0.002)\end{array}$ \\
\hline Felt hopeless most/all of time & $\begin{array}{l}0.05 \\
(0.004)\end{array}$ & $\begin{array}{l}0.02 * * * \\
(0.001)\end{array}$ \\
\hline Poor mental health & $\begin{array}{l}0.24 \\
(0.007)\end{array}$ & $\begin{array}{l}0.12 * * * \\
(0.003)\end{array}$ \\
\hline Obesity & $\begin{array}{l}0.37 \\
(0.009)\end{array}$ & $\begin{array}{l}0.28 * * * \\
(0.004)\end{array}$ \\
\hline Smoker & $\begin{array}{l}0.15 \\
(0.006)\end{array}$ & $\begin{array}{l}0.13 * * * \\
(0.003)\end{array}$ \\
\hline Pregnant & $\begin{array}{l}0.01 \\
(0.002)\end{array}$ & $\begin{array}{l}0.03 * * * \\
(0.001)\end{array}$ \\
\hline Angina & $\begin{array}{l}0.05 \\
(0.004)\end{array}$ & $\begin{array}{l}0.02 * * * \\
(0.001)\end{array}$ \\
\hline Arthritis & $\begin{array}{l}0.55 \\
(0.010)\end{array}$ & $\begin{array}{l}0.21 * * * \\
(0.004)\end{array}$ \\
\hline Asthma & $\begin{array}{l}0.14 \\
(0.007)\end{array}$ & $\begin{array}{l}0.09 * * * \\
(0.002)\end{array}$ \\
\hline Chronic bronchitis & $\begin{array}{l}0.04 \\
(0.003)\end{array}$ & $\begin{array}{l}0.01 * * * \\
(0.001)\end{array}$ \\
\hline Coronary heart disease & $\begin{array}{l}0.08 \\
(0.005)\end{array}$ & $\begin{array}{l}0.04 * * * \\
(0.001)\end{array}$ \\
\hline Cholesterol & $\begin{array}{l}0.47 \\
(0.010)\end{array}$ & $\begin{array}{l}0.27 * * * \\
(0.003)\end{array}$ \\
\hline Diabetes & $\begin{array}{l}0.16 \\
(0.006)\end{array}$ & $\begin{array}{l}0.09 * * * \\
(0.002)\end{array}$ \\
\hline Emphysema & $\begin{array}{l}0.05 \\
(0.004)\end{array}$ & $\begin{array}{l}0.02 * * * \\
(0.001)\end{array}$ \\
\hline High blood pressure & $\begin{array}{l}0.48 \\
(0.012)\end{array}$ & $\begin{array}{l}0.30 * * * \\
(0.004)\end{array}$ \\
\hline Joint pain & $\begin{array}{l}0.65 \\
(0.009)\end{array}$ & $\begin{array}{l}0.30 * * * \\
(0.005)\end{array}$ \\
\hline Mild heart attack & $\begin{array}{l}0.07 \\
(0.005)\end{array}$ & $\begin{array}{l}0.03 * * * \\
(0.001)\end{array}$ \\
\hline Other heart attack & $\begin{array}{l}0.18 \\
(0.008)\end{array}$ & $\begin{array}{l}0.10 * * * \\
(0.002)\end{array}$ \\
\hline Stroke & $\begin{array}{l}0.07 \\
(0.005)\end{array}$ & $\begin{array}{l}0.03 * * * \\
(0.001)\end{array}$ \\
\hline
\end{tabular}


Table 4 (continued)

\begin{tabular}{lll}
\hline Variables & $(1)$ & $(2)$ \\
& Chronic pain & Acute pain \\
\hline Observations & 4,982 & 39,614 \\
\hline
\end{tabular}

Standard errors in parentheses adjusted for complex survey design.

The difference between Chronic and Acute Pain is statistically significant at these levels: $* * * p<0.01 ; * * p<0.05 ; * p<0.1$

$\mathrm{MME}=$ Morphine Milligram Equivalents. 


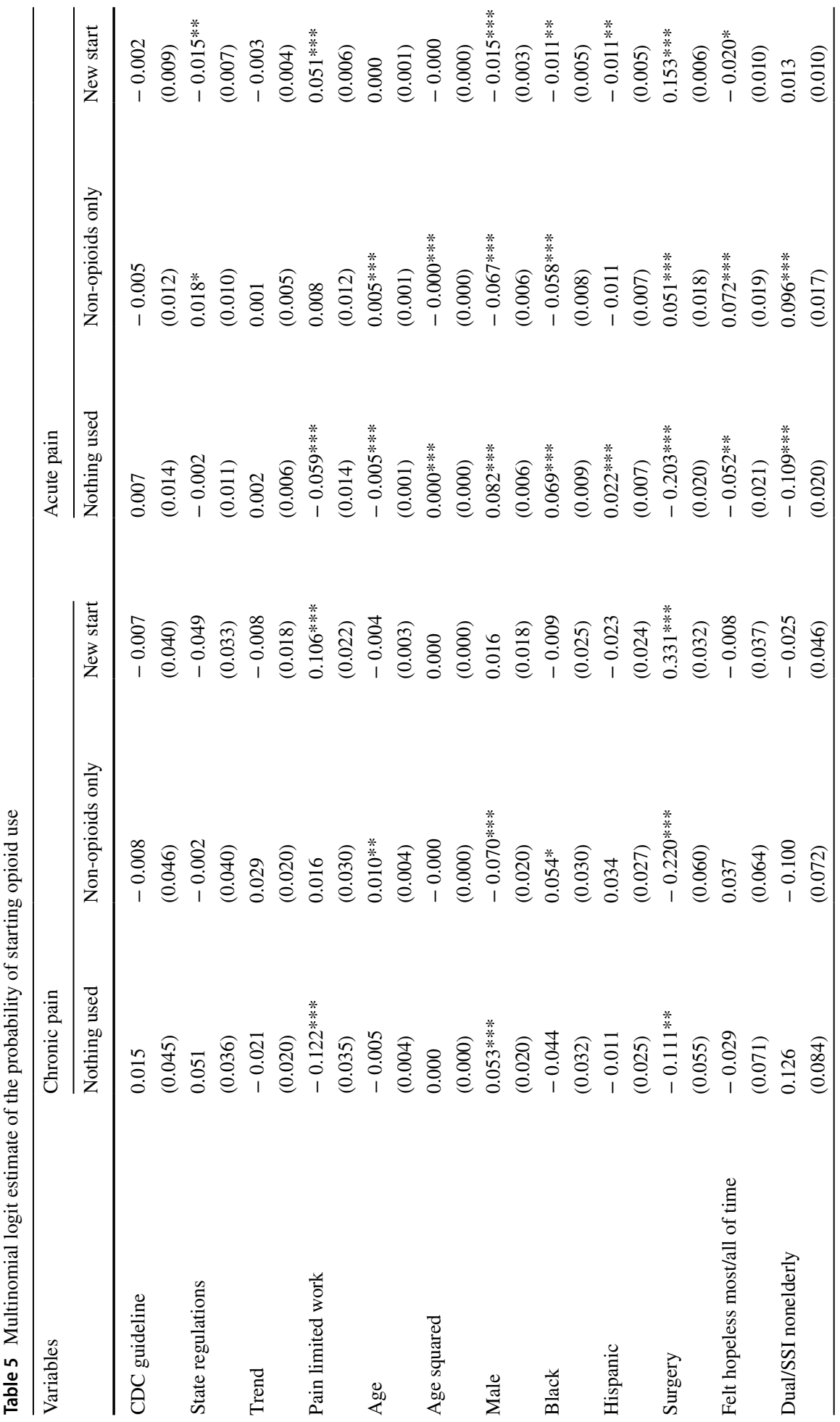




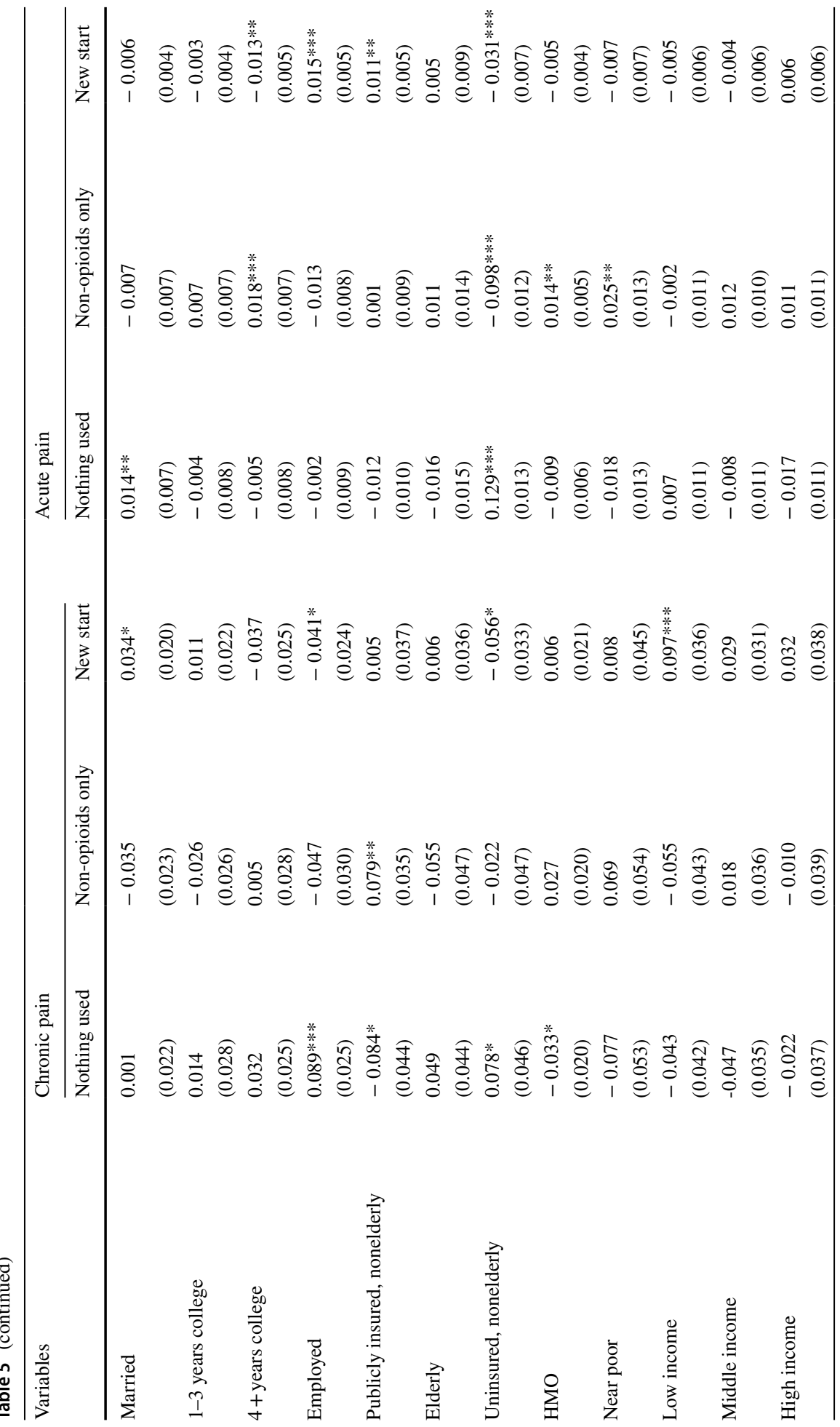




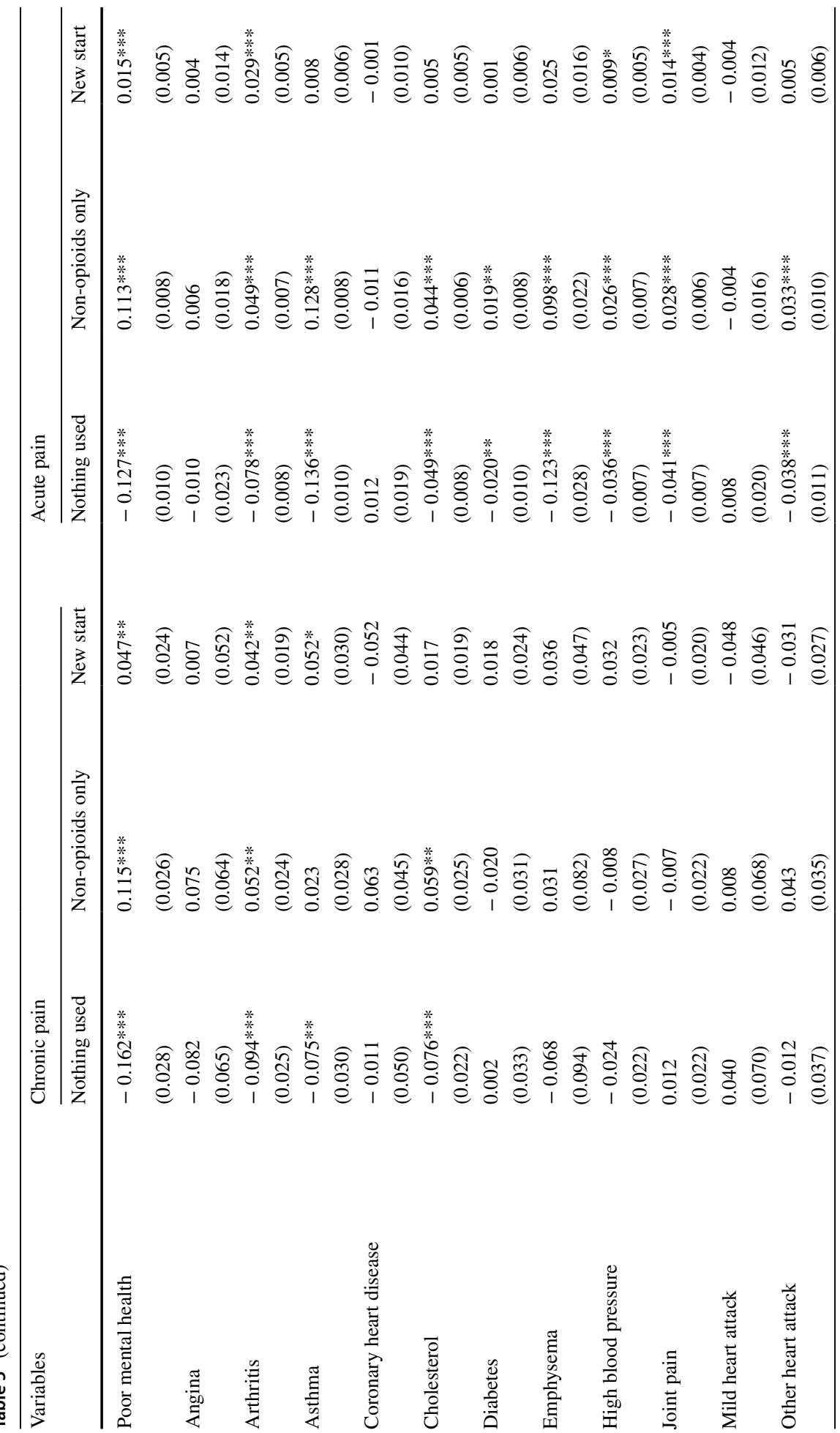




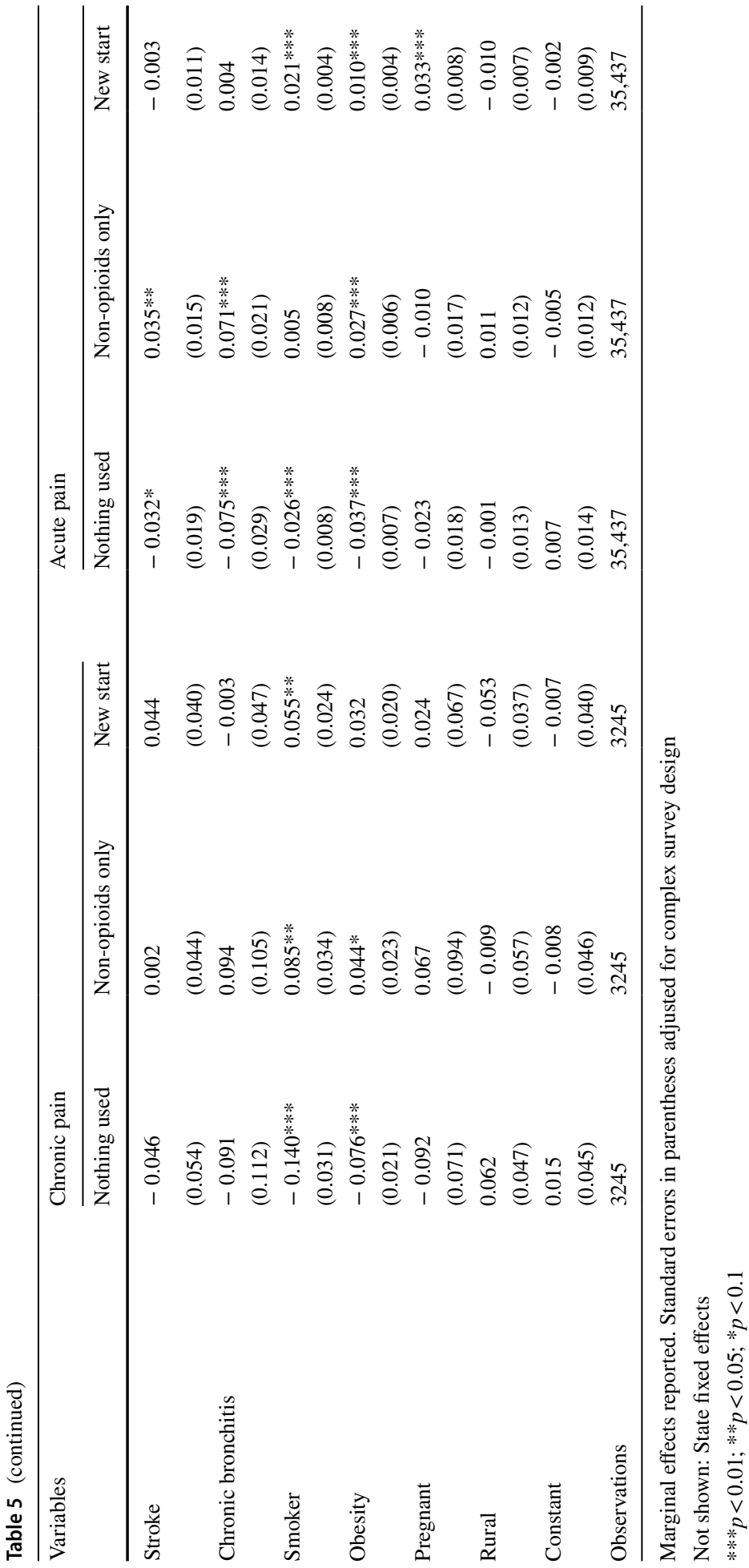


Table 6 Multinomial logit estimate of the relative risk ratios of starting opioid use

\begin{tabular}{|c|c|c|c|c|c|c|}
\hline \multirow[b]{2}{*}{ Variables } & \multicolumn{3}{|c|}{ Chronic pain } & \multicolumn{3}{|l|}{ Acute pain } \\
\hline & $\begin{array}{l}\text { Nothing } \\
\text { used (refer- } \\
\text { ence) }\end{array}$ & $\begin{array}{l}\text { Non-opioids } \\
\text { only }\end{array}$ & New start & $\begin{array}{l}\text { Nothing } \\
\text { used (refer- } \\
\text { ence) }\end{array}$ & $\begin{array}{l}\text { Non-opioids } \\
\text { only }\end{array}$ & New start \\
\hline \multirow[t]{2}{*}{ CDC Guideline } & & 0.930 & 0.910 & & 0.959 & 0.961 \\
\hline & & $(0.232)$ & $(0.296)$ & & $(0.090)$ & $(0.152)$ \\
\hline \multirow{2}{*}{$\begin{array}{l}\text { State Regula- } \\
\text { tions }\end{array}$} & & 0.826 & $0.628 *$ & & 1.109 & $0.790 *$ \\
\hline & & $(0.170)$ & $(0.166)$ & & $(0.082)$ & $(0.096)$ \\
\hline Observations & 3245 & 3245 & 3245 & 35,437 & 35,437 & 35,437 \\
\hline
\end{tabular}

Relative Risk Ratios reported relative to "nothing used." Standard errors in parentheses adjusted for complex survey design.

$* * * p<0.01 ; * * p<0.05 ; * p<0.1$ 


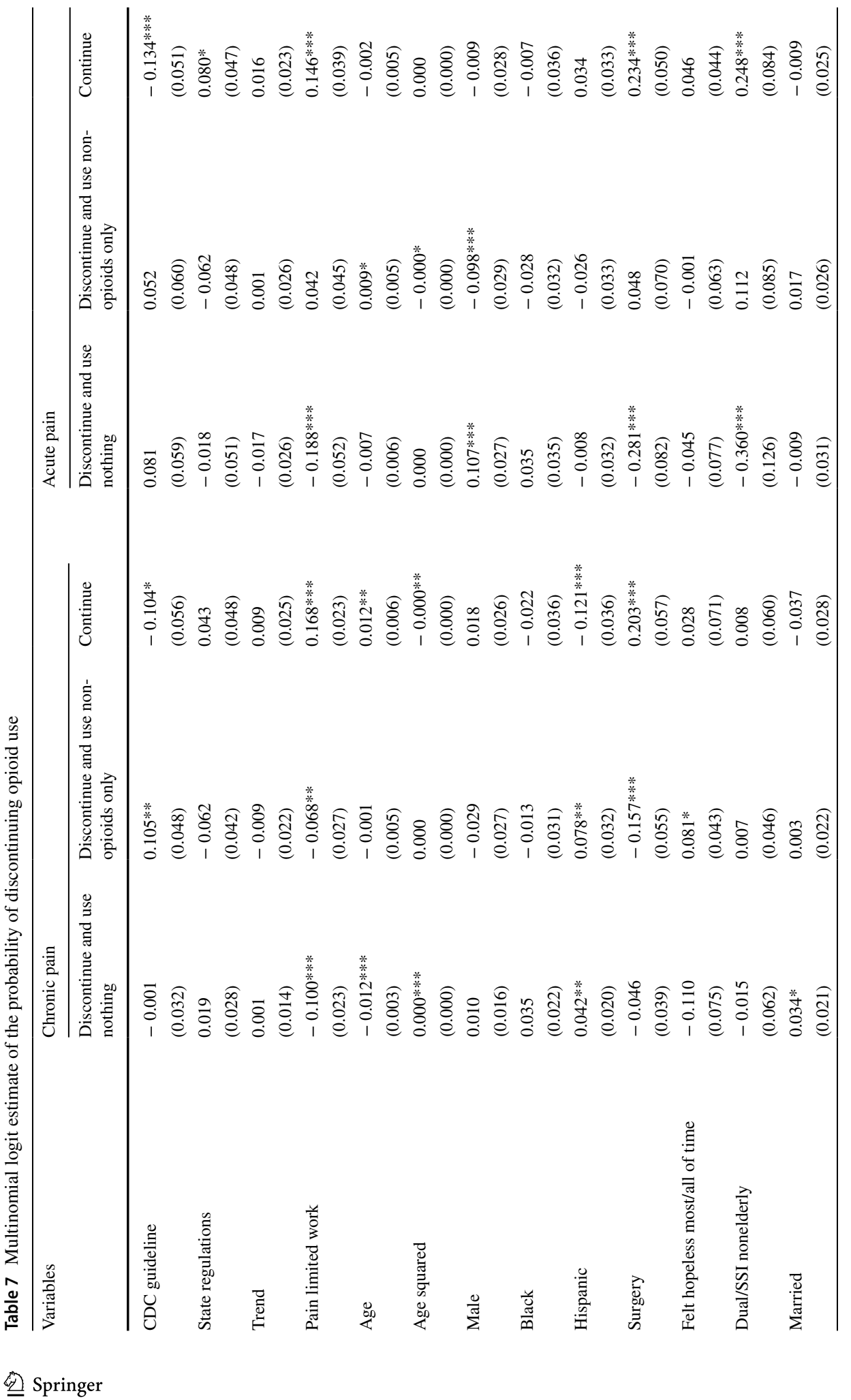




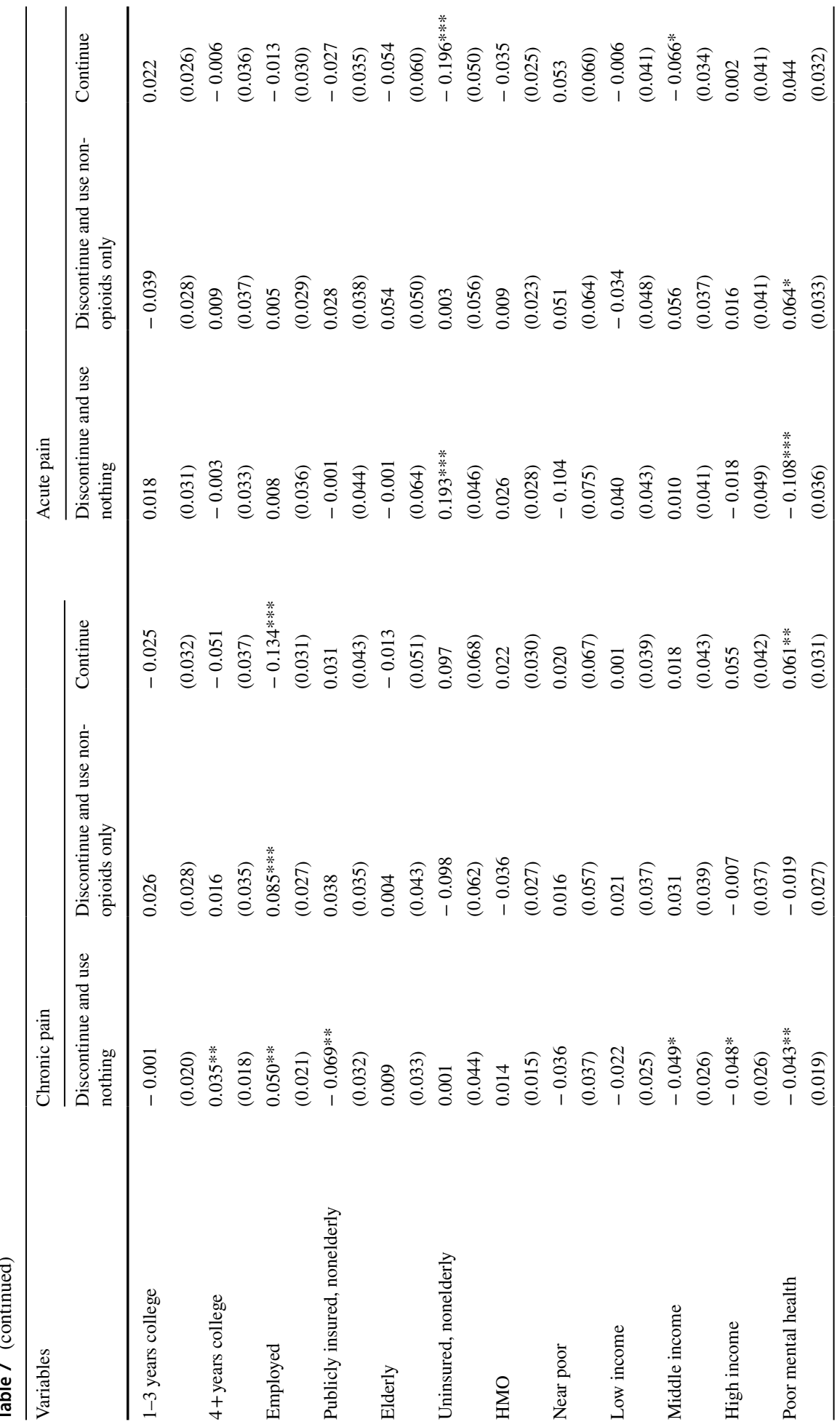




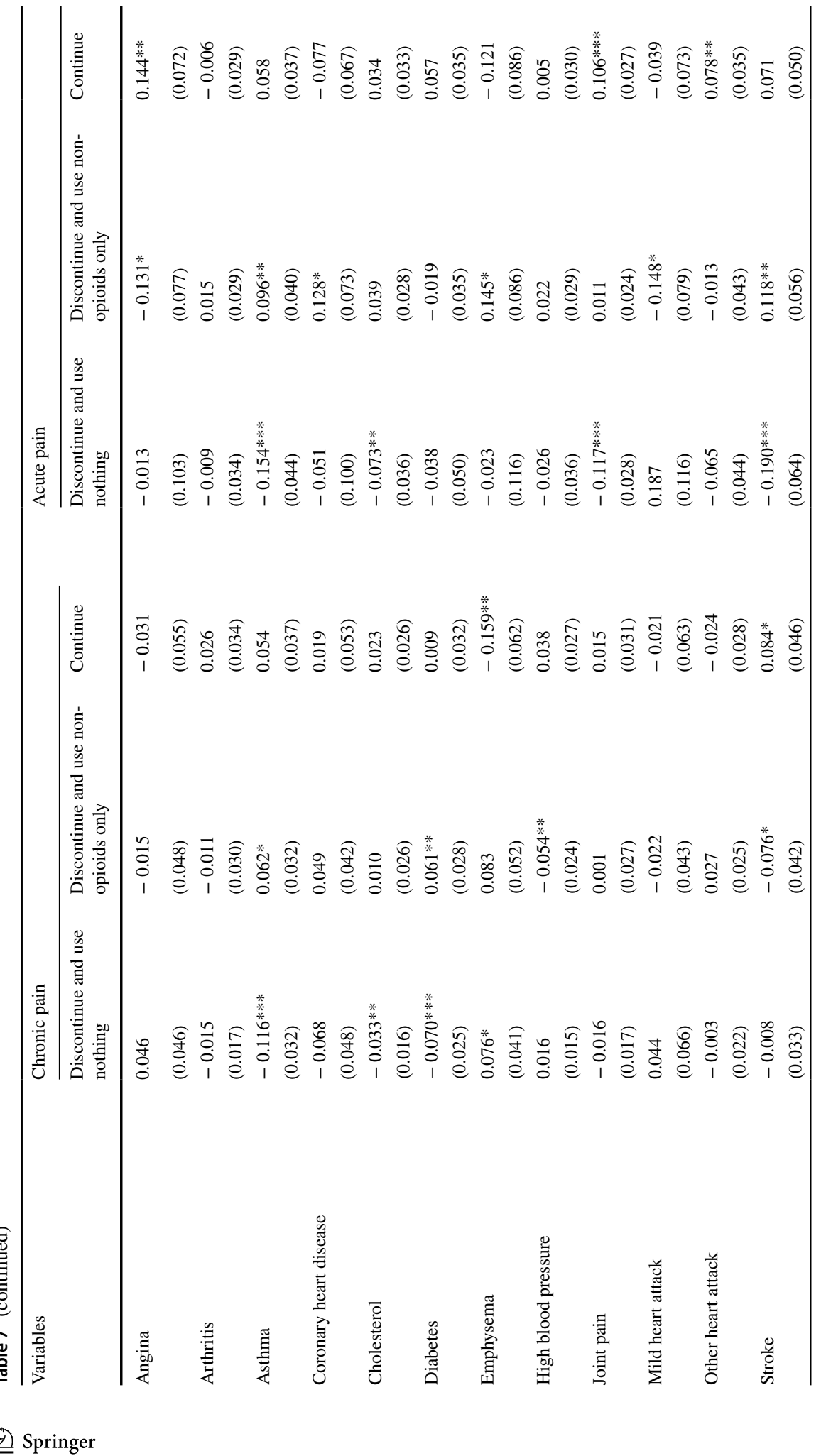




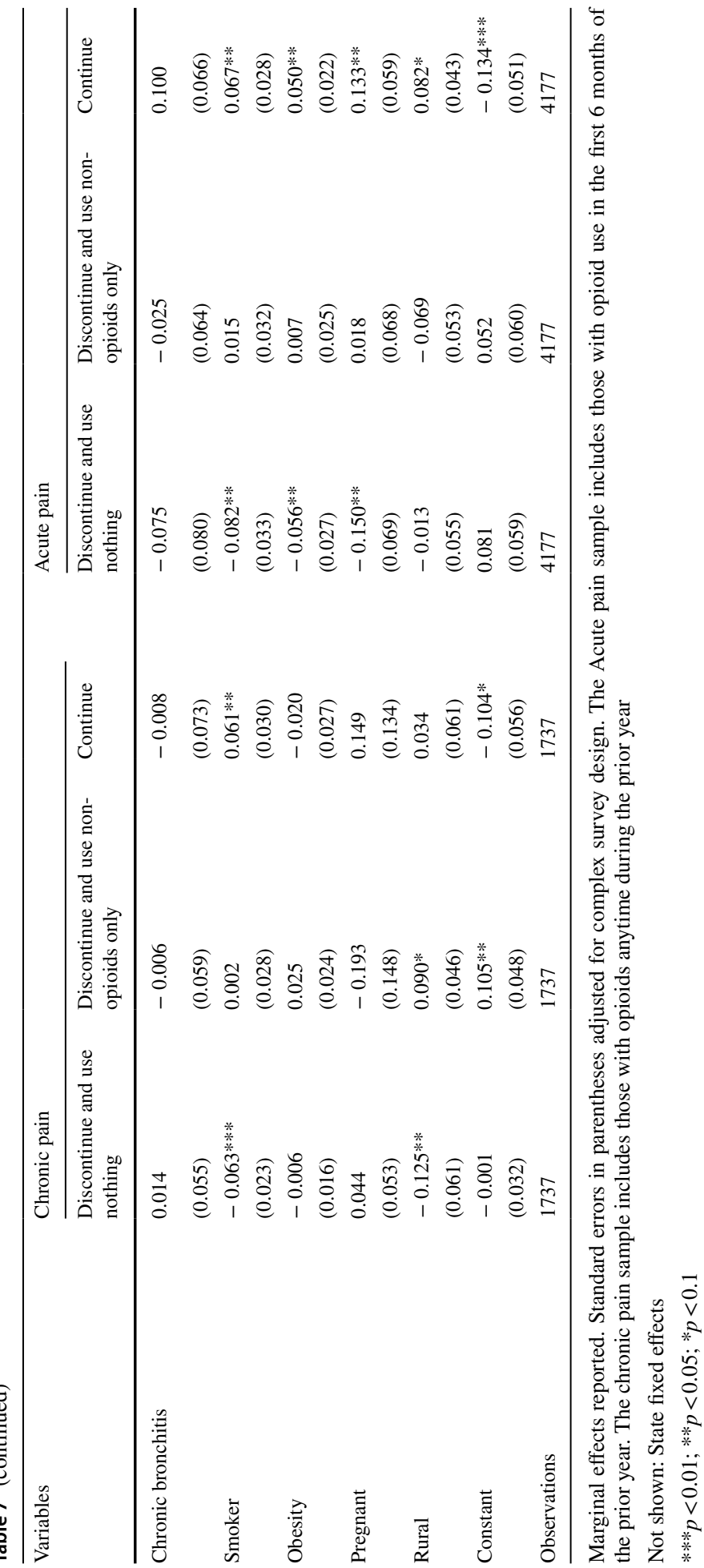




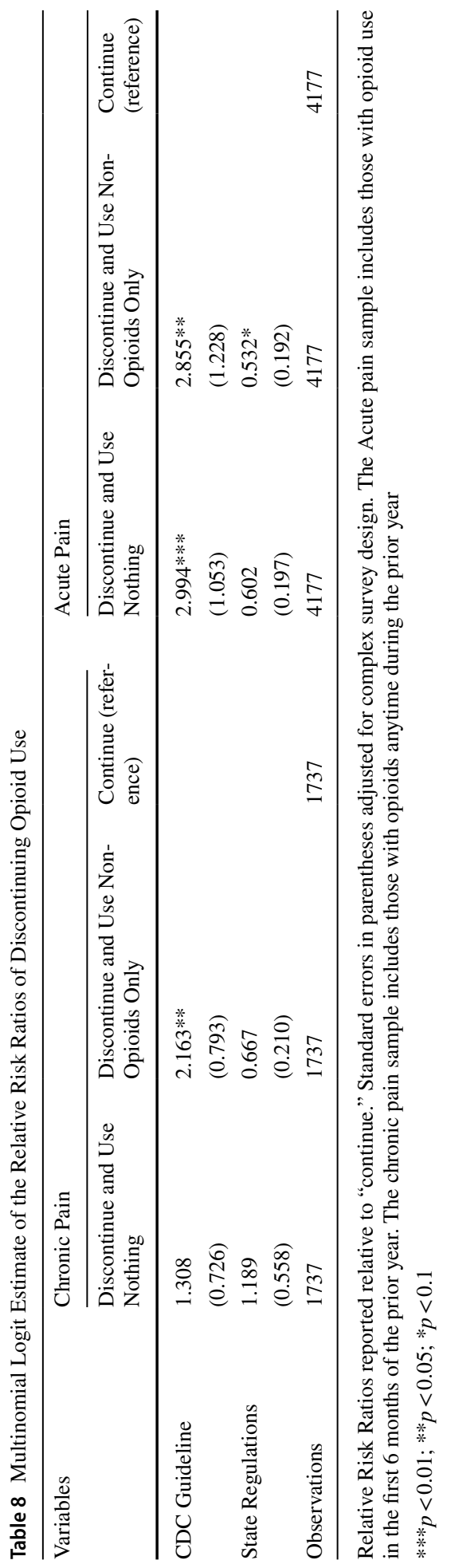


Table 9 Robustness check, multinomial logit estimate of the probability of discontinuing opioid use

\begin{tabular}{|c|c|c|c|c|c|c|}
\hline \multirow[t]{2}{*}{ Variables } & \multicolumn{3}{|l|}{ Chronic Pain } & \multicolumn{3}{|l|}{ Acute Pain } \\
\hline & $\begin{array}{l}\text { Discontinue } \\
\text { and use noth- } \\
\text { ing }\end{array}$ & $\begin{array}{l}\text { Discontinue } \\
\text { and use } \\
\text { non- opioids } \\
\text { only }\end{array}$ & Continue & $\begin{array}{l}\text { Discontinue } \\
\text { and use noth- } \\
\text { ing }\end{array}$ & $\begin{array}{l}\text { Discontinue } \\
\text { and use } \\
\text { non- opioids } \\
\text { only }\end{array}$ & Continue \\
\hline CDC guideline & $\begin{array}{l}-0.004 \\
(0.034)\end{array}$ & $\begin{array}{l}0.101 * * \\
(0.049)\end{array}$ & $\begin{array}{l}-0.097 \\
(0.059)\end{array}$ & $\begin{array}{r}0.080 \\
(0.059)\end{array}$ & $\begin{array}{c}0.051 \\
(0.059)\end{array}$ & $\begin{array}{l}-0.131 \text { ** } \\
(0.051)\end{array}$ \\
\hline $\begin{array}{l}\text { State regula- } \\
\text { tions }\end{array}$ & $\begin{array}{r}0.004 \\
(0.027)\end{array}$ & $\begin{array}{l}-0.058 \\
(0.042)\end{array}$ & $\begin{array}{r}0.053 \\
(0.050)\end{array}$ & $\begin{array}{l}-0.025 \\
(0.051)\end{array}$ & $\begin{array}{l}-0.061 \\
(0.048)\end{array}$ & $\begin{array}{l}0.086^{*} \\
(0.048)\end{array}$ \\
\hline
\end{tabular}

Marginal effects reported. As a robustness check, this version of eTable 7 excludes three covariates: pain limitations, hopelessness, and mental health status, in case they might be affected by stopping opioids. These results are consistent with eTable 7. Standard errors in parentheses adjusted for complex survey design

$* * * p<0.01 ; * * p<0.05 ; * p<0.1$ 
Table 10 Estimated probability of discontinuing opioid use among long-term users

\begin{tabular}{|c|c|c|}
\hline Variables & $\begin{array}{l}\text { (1) } \\
\text { Discontinue and use } \\
\text { non-opioids only }\end{array}$ & $\begin{array}{l}\text { (2) } \\
\text { Continue }\end{array}$ \\
\hline CDC guideline & $\begin{array}{l}0.100^{*} \\
(0.057)\end{array}$ & $\begin{array}{l}-0.115 * * \\
(0.057)\end{array}$ \\
\hline State regulations & $\begin{array}{l}-0.029 \\
(0.041)\end{array}$ & $\begin{array}{l}0.048 \\
(0.048)\end{array}$ \\
\hline Trend & $\begin{array}{l}-0.009 \\
(0.025)\end{array}$ & $\begin{array}{l}-0.004 \\
(0.025)\end{array}$ \\
\hline Pain limited work & $\begin{array}{l}-0.011 \\
(0.025)\end{array}$ & $\begin{array}{l}0.042 \\
(0.028)\end{array}$ \\
\hline Age & $\begin{array}{l}0.004 \\
(0.007)\end{array}$ & $\begin{array}{l}0.001 \\
(0.006)\end{array}$ \\
\hline Age squared & $\begin{array}{l}-0.000 \\
(0.000)\end{array}$ & $\begin{array}{l}0.000 \\
(0.000)\end{array}$ \\
\hline Male & $\begin{array}{l}-0.043 \\
(0.030)\end{array}$ & $\begin{array}{l}0.024 \\
(0.029)\end{array}$ \\
\hline Black & $\begin{array}{l}-0.041 \\
(0.042)\end{array}$ & $\begin{array}{l}0.017 \\
(0.044)\end{array}$ \\
\hline Hispanic & $\begin{array}{l}0.026 \\
(0.043)\end{array}$ & $\begin{array}{l}-0.053 \\
(0.044)\end{array}$ \\
\hline Surgery & $\begin{array}{l}-0.057 \\
(0.047)\end{array}$ & $\begin{array}{l}0.037 \\
(0.045)\end{array}$ \\
\hline Felt hopeless most/all of time & $\begin{array}{l}-0.028 \\
(0.047)\end{array}$ & $\begin{array}{l}0.026 \\
(0.047)\end{array}$ \\
\hline Dual/SSI nonelderly & $\begin{array}{l}-0.003 \\
(0.048)\end{array}$ & $\begin{array}{l}-0.003 \\
(0.055)\end{array}$ \\
\hline Married & $\begin{array}{l}-0.003 \\
(0.033)\end{array}$ & $\begin{array}{l}-0.034 \\
(0.038)\end{array}$ \\
\hline $1-3$ years college & $\begin{array}{l}-0.019 \\
(0.042)\end{array}$ & $\begin{array}{l}0.001 \\
(0.042)\end{array}$ \\
\hline $4+$ years college & $\begin{array}{l}0.030 \\
(0.040)\end{array}$ & $\begin{array}{l}-0.050 \\
(0.044)\end{array}$ \\
\hline Employed & $\begin{array}{l}0.065^{*} \\
(0.036)\end{array}$ & $\begin{array}{l}-0.124 * * * \\
(0.042)\end{array}$ \\
\hline Publicly insured, nonelderly & $\begin{array}{l}-0.032 \\
(0.044)\end{array}$ & $\begin{array}{l}0.046 \\
(0.047)\end{array}$ \\
\hline Elderly & $\begin{array}{l}0.048 \\
(0.041)\end{array}$ & $\begin{array}{l}-0.091 * * \\
(0.046)\end{array}$ \\
\hline Uninsured, nonelderly & $\begin{array}{l}-0.251 * * \\
(0.106)\end{array}$ & $\begin{array}{l}0.333 * * * \\
(0.126)\end{array}$ \\
\hline HMO & $\begin{array}{l}-0.094 * * * \\
(0.030)\end{array}$ & $\begin{array}{l}0.096 * * * \\
(0.032)\end{array}$ \\
\hline Near poor & $\begin{array}{l}0.024 \\
(0.070)\end{array}$ & $\begin{array}{l}-0.002 \\
(0.077)\end{array}$ \\
\hline Low income & $\begin{array}{l}-0.017 \\
(0.047)\end{array}$ & $\begin{array}{l}0.047 \\
(0.047)\end{array}$ \\
\hline
\end{tabular}


Table 10 (continued)

\begin{tabular}{|c|c|c|}
\hline Variables & $\begin{array}{l}\text { (1) } \\
\text { Discontinue and use } \\
\text { non-opioids only }\end{array}$ & $\begin{array}{l}(2) \\
\text { Continue }\end{array}$ \\
\hline Middle income & $\begin{array}{l}-0.027 \\
(0.053)\end{array}$ & $\begin{array}{l}0.111^{*} \\
(0.058)\end{array}$ \\
\hline High income & $\begin{array}{l}-0.041 \\
(0.053)\end{array}$ & $\begin{array}{l}0.100^{*} \\
(0.056)\end{array}$ \\
\hline Poor mental health & $\begin{array}{l}-0.039 \\
(0.041)\end{array}$ & $\begin{array}{l}0.016 \\
(0.041)\end{array}$ \\
\hline Angina & $\begin{array}{l}0.025 \\
(0.043)\end{array}$ & $\begin{array}{l}-0.046 \\
(0.052)\end{array}$ \\
\hline Arthritis & $\begin{array}{l}-0.004 \\
(0.045)\end{array}$ & $\begin{array}{l}0.028 \\
(0.044)\end{array}$ \\
\hline Asthma & $\begin{array}{l}0.053 \\
(0.041)\end{array}$ & $\begin{array}{l}-0.020 \\
(0.044)\end{array}$ \\
\hline Coronary heart disease & $\begin{array}{l}0.030 \\
(0.039)\end{array}$ & $\begin{array}{l}0.045 \\
(0.052)\end{array}$ \\
\hline Cholesterol & $\begin{array}{l}-0.052 * \\
(0.029)\end{array}$ & $\begin{array}{l}0.046 \\
(0.029)\end{array}$ \\
\hline Diabetes & $\begin{array}{l}0.095 * * * \\
(0.036)\end{array}$ & $\begin{array}{l}-0.097^{* * *} \\
(0.035)\end{array}$ \\
\hline Emphysema & $\begin{array}{l}0.071^{*} \\
(0.038)\end{array}$ & $\begin{array}{l}-0.120^{* * *} \\
(0.045)\end{array}$ \\
\hline High blood pressure & $\begin{array}{l}-0.000 \\
(0.030)\end{array}$ & $\begin{array}{l}-0.002 \\
(0.030)\end{array}$ \\
\hline Joint pain & $\begin{array}{l}0.046 \\
(0.038)\end{array}$ & $\begin{array}{l}-0.065 \\
(0.040)\end{array}$ \\
\hline Mild heart attack & $\begin{array}{l}0.013 \\
(0.035)\end{array}$ & $\begin{array}{l}-0.049 \\
(0.047)\end{array}$ \\
\hline Other heart attack & $\begin{array}{l}0.001 \\
(0.038)\end{array}$ & $\begin{array}{l}-0.011 \\
(0.044)\end{array}$ \\
\hline Stroke & $\begin{array}{l}-0.047 \\
(0.038)\end{array}$ & $\begin{array}{l}0.091^{*} \\
(0.049)\end{array}$ \\
\hline Chronic bronchitis & $\begin{array}{l}0.014 \\
(0.064)\end{array}$ & $\begin{array}{l}-0.026 \\
(0.069)\end{array}$ \\
\hline Smoker & $\begin{array}{l}0.008 \\
(0.032)\end{array}$ & $\begin{array}{l}0.011 \\
(0.037)\end{array}$ \\
\hline Obesity & $\begin{array}{l}-0.036 \\
(0.031)\end{array}$ & $\begin{array}{l}0.040 \\
(0.031)\end{array}$ \\
\hline Rural & $\begin{array}{l}-0.137 * \\
(0.079)\end{array}$ & $\begin{array}{l}0.190 * * \\
(0.090)\end{array}$ \\
\hline Observations & 735 & 735 \\
\hline
\end{tabular}

Marginal effects reported. Less than $1 \%$ selected the option "Discontinue and use nothing," so that option could not be analyzed. Longterm use is more than 2 years, with chronic pain, excluding cancer. Standard errors in parentheses adjusted for complex survey design. Not shown: State fixed effects

$* * * p<0.01 ; * * p<0.05 ; * p<0.1$ 
Table 11 Estimated change in number of opioid prescriptions filled from prior year to current year among long-term users, 2014-2017

\begin{tabular}{|c|c|c|}
\hline Variables & $\begin{array}{l}\text { (1) } \\
\text { Probability of a decrease in annual } \\
\text { number of fills }\end{array}$ & $\begin{array}{l}(2) \\
\text { Change in num- } \\
\text { ber of annual } \\
\text { fills }\end{array}$ \\
\hline CDC guideline & $\begin{array}{l}0.961 * * \\
(0.420)\end{array}$ & $\begin{array}{l}-1.974^{*} \\
(1.134)\end{array}$ \\
\hline State regulations & $\begin{array}{l}0.085 \\
(0.429)\end{array}$ & $\begin{array}{l}0.360 \\
(0.921)\end{array}$ \\
\hline Trend & $\begin{array}{l}-0.431 * * \\
(0.176)\end{array}$ & $\begin{array}{l}0.772 \\
(0.472)\end{array}$ \\
\hline Pain limited work & $\begin{array}{l}-0.282 \\
(0.237)\end{array}$ & $\begin{array}{l}0.929 * \\
(0.543)\end{array}$ \\
\hline Age & $\begin{array}{l}0.030 \\
(0.067)\end{array}$ & $\begin{array}{l}-0.049 \\
(0.139)\end{array}$ \\
\hline Age squared & $\begin{array}{l}-0.000 \\
(0.001)\end{array}$ & $\begin{array}{l}0.001 \\
(0.001)\end{array}$ \\
\hline Male & $\begin{array}{l}-0.395^{*} \\
(0.225)\end{array}$ & $\begin{array}{l}0.391 \\
(0.441)\end{array}$ \\
\hline Black & $\begin{array}{l}0.132 \\
(0.253)\end{array}$ & $\begin{array}{l}0.513 \\
(0.548)\end{array}$ \\
\hline Hispanic & $\begin{array}{l}-0.159 \\
(0.321)\end{array}$ & $\begin{array}{l}1.409 * \\
(0.823)\end{array}$ \\
\hline Surgery & $\begin{array}{l}0.123 \\
(0.286)\end{array}$ & $\begin{array}{l}0.774 \\
(0.804)\end{array}$ \\
\hline Felt hopeless most/all of time & $\begin{array}{l}0.483 \\
(0.329)\end{array}$ & $\begin{array}{l}-1.061 \\
(0.761)\end{array}$ \\
\hline Dual/SSI nonelderly & $\begin{array}{l}0.411 \\
(0.316)\end{array}$ & $\begin{array}{l}0.156 \\
(0.763)\end{array}$ \\
\hline Married & $\begin{array}{l}0.116 \\
(0.257)\end{array}$ & $\begin{array}{l}-0.277 \\
(0.549)\end{array}$ \\
\hline $1-3$ years college & $\begin{array}{l}0.074 \\
(0.239)\end{array}$ & $\begin{array}{l}0.011 \\
(0.601)\end{array}$ \\
\hline $4+$ years college & $\begin{array}{l}0.300 \\
(0.309)\end{array}$ & $\begin{array}{l}-0.593 \\
(0.874)\end{array}$ \\
\hline Employed & $\begin{array}{l}0.266 \\
(0.292)\end{array}$ & $\begin{array}{l}-1.052 * \\
(0.630)\end{array}$ \\
\hline Publicly insured, nonelderly & $\begin{array}{l}-0.114 \\
(0.356)\end{array}$ & $\begin{array}{l}-0.445 \\
(0.787)\end{array}$ \\
\hline Elderly & $\begin{array}{l}0.558 \\
(0.374)\end{array}$ & $\begin{array}{l}-1.297 \\
(0.939)\end{array}$ \\
\hline Uninsured, nonelderly & $\begin{array}{l}0.461 \\
(0.525)\end{array}$ & $\begin{array}{l}-1.278 \\
(1.617)\end{array}$ \\
\hline HMO & $\begin{array}{l}0.260 \\
(0.229)\end{array}$ & $\begin{array}{l}-0.507 \\
(0.474)\end{array}$ \\
\hline
\end{tabular}


Table 11 (continued)

\begin{tabular}{|c|c|c|}
\hline Variables & $\begin{array}{l}\text { (1) } \\
\text { Probability of a decrease in annual } \\
\text { number of fills }\end{array}$ & $\begin{array}{l}\text { (2) } \\
\text { Change in num- } \\
\text { ber of annual } \\
\text { fills }\end{array}$ \\
\hline Near poor & $\begin{array}{l}-0.507 \\
(0.435)\end{array}$ & $\begin{array}{l}1.542 \\
(1.104)\end{array}$ \\
\hline Low income & $\begin{array}{l}-0.192 \\
(0.330)\end{array}$ & $\begin{array}{l}0.277 \\
(0.745)\end{array}$ \\
\hline Middle Income & $\begin{array}{l}-0.903 * * * \\
(0.336)\end{array}$ & $\begin{array}{l}1.680^{* *} \\
(0.714)\end{array}$ \\
\hline High Income & $\begin{array}{l}-0.628^{*} \\
(0.357)\end{array}$ & $\begin{array}{l}1.172 \\
(0.893)\end{array}$ \\
\hline Poor mental health & $\begin{array}{l}-0.301 \\
(0.245)\end{array}$ & $\begin{array}{l}0.064 \\
(0.548)\end{array}$ \\
\hline Angina & $\begin{array}{l}-0.099 \\
(0.429)\end{array}$ & $\begin{array}{l}-0.856 \\
(1.141)\end{array}$ \\
\hline Arthritis & $\begin{array}{l}0.245 \\
(0.307)\end{array}$ & $\begin{array}{l}0.365 \\
(0.651)\end{array}$ \\
\hline Asthma & $\begin{array}{l}-0.222 \\
(0.292)\end{array}$ & $\begin{array}{l}0.196 \\
(0.624)\end{array}$ \\
\hline Coronary heart disease & $\begin{array}{l}-0.797 * * \\
(0.374)\end{array}$ & $\begin{array}{l}1.617 * \\
(0.935)\end{array}$ \\
\hline Cholesterol & $\begin{array}{l}-0.052 \\
(0.217)\end{array}$ & $\begin{array}{l}-0.597 \\
(0.563)\end{array}$ \\
\hline Diabetes & $\begin{array}{l}-0.446 \\
(0.273)\end{array}$ & $\begin{array}{l}0.930 \\
(0.581)\end{array}$ \\
\hline Emphysema & $\begin{array}{l}0.082 \\
(0.375)\end{array}$ & $\begin{array}{l}-1.353 \\
(0.952)\end{array}$ \\
\hline High blood pressure & $\begin{array}{l}0.045 \\
(0.279)\end{array}$ & $\begin{array}{l}-0.369 \\
(0.586)\end{array}$ \\
\hline Joint pain & $\begin{array}{l}0.211 \\
(0.287)\end{array}$ & $\begin{array}{l}-0.509 \\
(0.634)\end{array}$ \\
\hline Mild heart attack & $\begin{array}{l}1.065^{* * * *} \\
(0.358)\end{array}$ & $\begin{array}{l}-2.010^{* * * *} \\
(0.761)\end{array}$ \\
\hline Other heart attack & $\begin{array}{l}0.301 \\
(0.269)\end{array}$ & $\begin{array}{l}-0.236 \\
(0.644)\end{array}$ \\
\hline Stroke & $\begin{array}{l}0.102 \\
(0.303)\end{array}$ & $\begin{array}{l}-0.825 \\
(0.840)\end{array}$ \\
\hline Chronic bronchitis & $\begin{array}{l}0.070 \\
(0.419)\end{array}$ & $\begin{array}{l}0.159 \\
(1.145)\end{array}$ \\
\hline Smoker & $\begin{array}{l}-0.366 \\
(0.229)\end{array}$ & $\begin{array}{l}1.365^{* *} \\
(0.595)\end{array}$ \\
\hline Obesity & $\begin{array}{l}-0.033 \\
(0.225)\end{array}$ & $\begin{array}{l}0.495 \\
(0.559)\end{array}$ \\
\hline Pregnant & $\begin{array}{l}0.899 \\
(1.430)\end{array}$ & $\begin{array}{l}0.893 \\
(1.899)\end{array}$ \\
\hline
\end{tabular}


Table 11 (continued)

\begin{tabular}{lll}
\hline Variables & $\begin{array}{l}(1) \\
\text { Probability of a decrease in annual } \\
\text { number of fills }\end{array}$ & $\begin{array}{l}\text { (2) } \\
\text { Change in num- } \\
\text { ber of annual } \\
\text { fills }\end{array}$ \\
\hline Rural & 0.401 & 0.569 \\
Constant & $(0.389)$ & $(0.911)$ \\
& 0.407 & -1.037 \\
Observations & $(1.756)$ & $(3.890)$ \\
R-squared & 735 & 735 \\
\hline
\end{tabular}

Col 1: Logit. Col 2: Linear regression. Marginal effects reported. Long-term use is more than 2 years, with chronic pain, excluding cancer. Standard errors in parentheses adjusted for complex survey design

Not shown: State fixed effects

$* * * p<0.01 ; * * p<0.05 ; * p<0.1$ 
Table 12 Estimated use of annual mmes among long-term users, 2014-2017

\begin{tabular}{|c|c|c|}
\hline \multirow[t]{2}{*}{ Variables } & (1) & (2) \\
\hline & $\begin{array}{l}\text { Probability of using less than } 700 \text { annual } \\
\text { MMEs }\end{array}$ & $\begin{array}{l}\text { Probability of using more } \\
\text { than } 3000 \text { annual MMEs }\end{array}$ \\
\hline \multirow[t]{2}{*}{ CDC guideline } & $0.109^{*}$ & -0.020 \\
\hline & $(0.061)$ & $(0.090)$ \\
\hline \multirow[t]{2}{*}{ State regulations } & -0.021 & 0.102 \\
\hline & $(0.063)$ & $(0.078)$ \\
\hline \multirow[t]{2}{*}{ Trend } & $-0.050^{*}$ & -0.006 \\
\hline & $(0.029)$ & $(0.045)$ \\
\hline \multirow[t]{2}{*}{ Pain limited work } & $-0.076^{* * *}$ & $0.152 * * *$ \\
\hline & $(0.029)$ & $(0.043)$ \\
\hline \multirow[t]{2}{*}{ Age } & $-0.022 * * *$ & $0.022 * *$ \\
\hline & $(0.008)$ & $(0.010)$ \\
\hline \multirow[t]{2}{*}{ Age squared } & $0.000 * * *$ & $-0.000^{* * *}$ \\
\hline & $(0.000)$ & $(0.000)$ \\
\hline \multirow[t]{2}{*}{ Male } & -0.016 & 0.003 \\
\hline & $(0.032)$ & $(0.041)$ \\
\hline \multirow[t]{2}{*}{ Black } & 0.064 & $-0.125^{* *}$ \\
\hline & $(0.043)$ & $(0.054)$ \\
\hline \multirow[t]{2}{*}{ Hispanic } & 0.063 & $-0.158 * * *$ \\
\hline & $(0.048)$ & $(0.059)$ \\
\hline \multirow[t]{2}{*}{ Surgery } & -0.031 & 0.087 \\
\hline & $(0.047)$ & $(0.066)$ \\
\hline \multirow[t]{2}{*}{ Felt hopeless most/all of time } & $0.110^{*}$ & 0.002 \\
\hline & $(0.061)$ & $(0.078)$ \\
\hline \multirow[t]{2}{*}{ Dual/SSI nonelderly } & -0.030 & -0.072 \\
\hline & $(0.046)$ & $(0.067)$ \\
\hline \multirow[t]{2}{*}{ Married } & -0.020 & -0.043 \\
\hline & $(0.038)$ & $(0.045)$ \\
\hline \multirow[t]{2}{*}{$1-3$ years college } & $0.092 * * *$ & $-0.080^{*}$ \\
\hline & $(0.031)$ & $(0.044)$ \\
\hline \multirow[t]{2}{*}{$4+$ years college } & 0.013 & $-0.134 * *$ \\
\hline & $(0.042)$ & $(0.054)$ \\
\hline \multirow[t]{2}{*}{ Employed } & 0.051 & $-0.272 * * *$ \\
\hline & $(0.037)$ & $(0.046)$ \\
\hline \multirow[t]{2}{*}{ Publicly insured, nonelderly } & -0.022 & 0.029 \\
\hline & $(0.045)$ & $(0.063)$ \\
\hline \multirow[t]{2}{*}{ Elderly } & $-0.233^{* * *}$ & 0.120 \\
\hline & $(0.074)$ & $(0.075)$ \\
\hline \multirow[t]{2}{*}{ Uninsured, nonelderly } & -0.041 & -0.027 \\
\hline & $(0.082)$ & $(0.087)$ \\
\hline \multirow[t]{2}{*}{ HMO } & -0.006 & 0.013 \\
\hline & $(0.030)$ & $(0.040)$ \\
\hline \multirow[t]{2}{*}{ Near poor } & $-0.168^{*}$ & 0.115 \\
\hline & $(0.098)$ & $(0.087)$ \\
\hline \multirow[t]{2}{*}{ Low income } & -0.072 & 0.099 \\
\hline & $(0.057)$ & $(0.071)$ \\
\hline \multirow[t]{2}{*}{ Middle income } & $-0.092 *$ & $0.185^{* * *}$ \\
\hline & $(0.050)$ & $(0.071)$ \\
\hline
\end{tabular}


Table 12 (continued)

\begin{tabular}{|c|c|c|}
\hline \multirow[t]{2}{*}{ Variables } & (1) & (2) \\
\hline & $\begin{array}{l}\text { Probability of using less than } 700 \text { annual } \\
\text { MMEs }\end{array}$ & $\begin{array}{l}\text { Probability of using more } \\
\text { than } 3000 \text { annual MMEs }\end{array}$ \\
\hline \multirow[t]{2}{*}{ High income } & $-0.105^{*}$ & $0.156^{* *}$ \\
\hline & $(0.060)$ & $(0.074)$ \\
\hline \multirow[t]{2}{*}{ Poor mental health } & $-0.060 *$ & 0.017 \\
\hline & $(0.034)$ & $(0.042)$ \\
\hline \multirow[t]{2}{*}{ Angina } & -0.130 & 0.030 \\
\hline & $(0.084)$ & $(0.068)$ \\
\hline \multirow[t]{2}{*}{ Arthritis } & -0.045 & 0.011 \\
\hline & $(0.043)$ & $(0.051)$ \\
\hline \multirow[t]{2}{*}{ Asthma } & 0.029 & 0.023 \\
\hline & $(0.042)$ & $(0.059)$ \\
\hline \multirow[t]{2}{*}{ Coronary heart disease } & -0.020 & 0.005 \\
\hline & $(0.064)$ & $(0.076)$ \\
\hline \multirow[t]{2}{*}{ Cholesterol } & 0.023 & 0.009 \\
\hline & $(0.032)$ & $(0.044)$ \\
\hline \multirow[t]{2}{*}{ Diabetes } & 0.010 & -0.003 \\
\hline & $(0.038)$ & $(0.047)$ \\
\hline \multirow[t]{2}{*}{ Emphysema } & -0.007 & $-0.169^{* * *}$ \\
\hline & $(0.068)$ & $(0.064)$ \\
\hline \multirow[t]{2}{*}{ High blood pressure } & -0.013 & $0.093^{* *}$ \\
\hline & $(0.030)$ & $(0.047)$ \\
\hline \multirow[t]{2}{*}{ Joint pain } & -0.030 & 0.043 \\
\hline & $(0.036)$ & $(0.054)$ \\
\hline \multirow[t]{2}{*}{ Mild heart attack } & 0.017 & -0.010 \\
\hline & $(0.060)$ & $(0.077)$ \\
\hline \multirow[t]{2}{*}{ Other heart attack } & 0.010 & -0.007 \\
\hline & $(0.037)$ & $(0.044)$ \\
\hline \multirow[t]{2}{*}{ Stroke } & 0.002 & -0.085 \\
\hline & $(0.054)$ & $(0.064)$ \\
\hline \multirow[t]{2}{*}{ Chronic bronchitis } & -0.010 & 0.052 \\
\hline & $(0.060)$ & $(0.094)$ \\
\hline \multirow[t]{2}{*}{ Smoker } & $-0.071 *$ & $0.092 *$ \\
\hline & $(0.040)$ & $(0.048)$ \\
\hline \multirow[t]{2}{*}{ Obesity } & -0.044 & 0.004 \\
\hline & $(0.030)$ & $(0.045)$ \\
\hline \multirow[t]{2}{*}{ Pregnant } & 0.157 & -0.363 \\
\hline & $(0.122)$ & $(0.269)$ \\
\hline \multirow[t]{2}{*}{ Rural } & -0.083 & 0.021 \\
\hline & $(0.057)$ & $(0.064)$ \\
\hline Observations & 735 & 735 \\
\hline
\end{tabular}

Logit regressions. Marginal effects reported. Long-term use is more than 2 years, with chronic pain, excluding cancer

Standing AHRQ An parentheses adjusted for complex survey design

Declahations State fixed effects

$M M E$ morphine milligram equivalents

Conflicts of interest ${ }^{*}$. Phe a ${ }^{*}$ authors declare that they have no conflict of interest. 


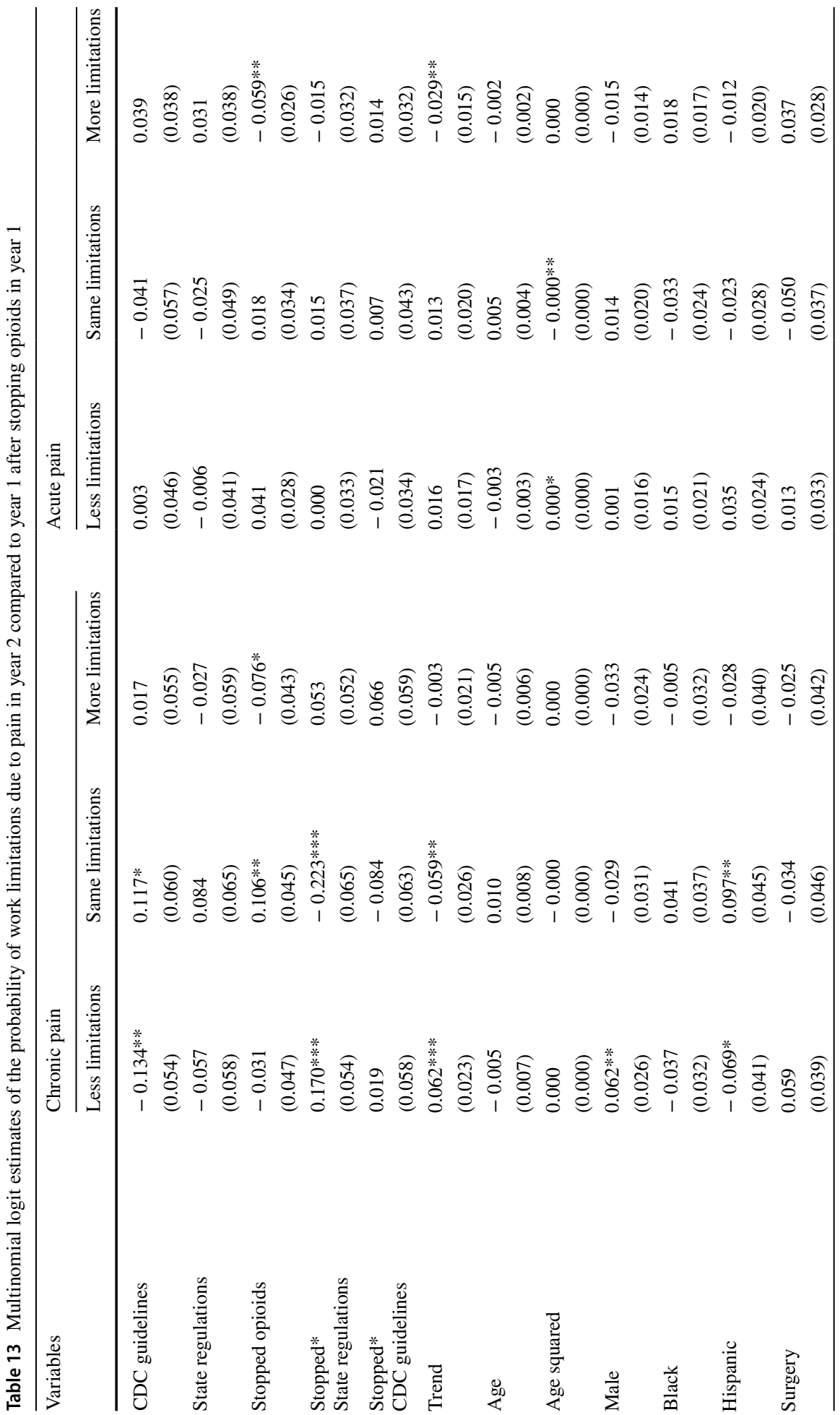




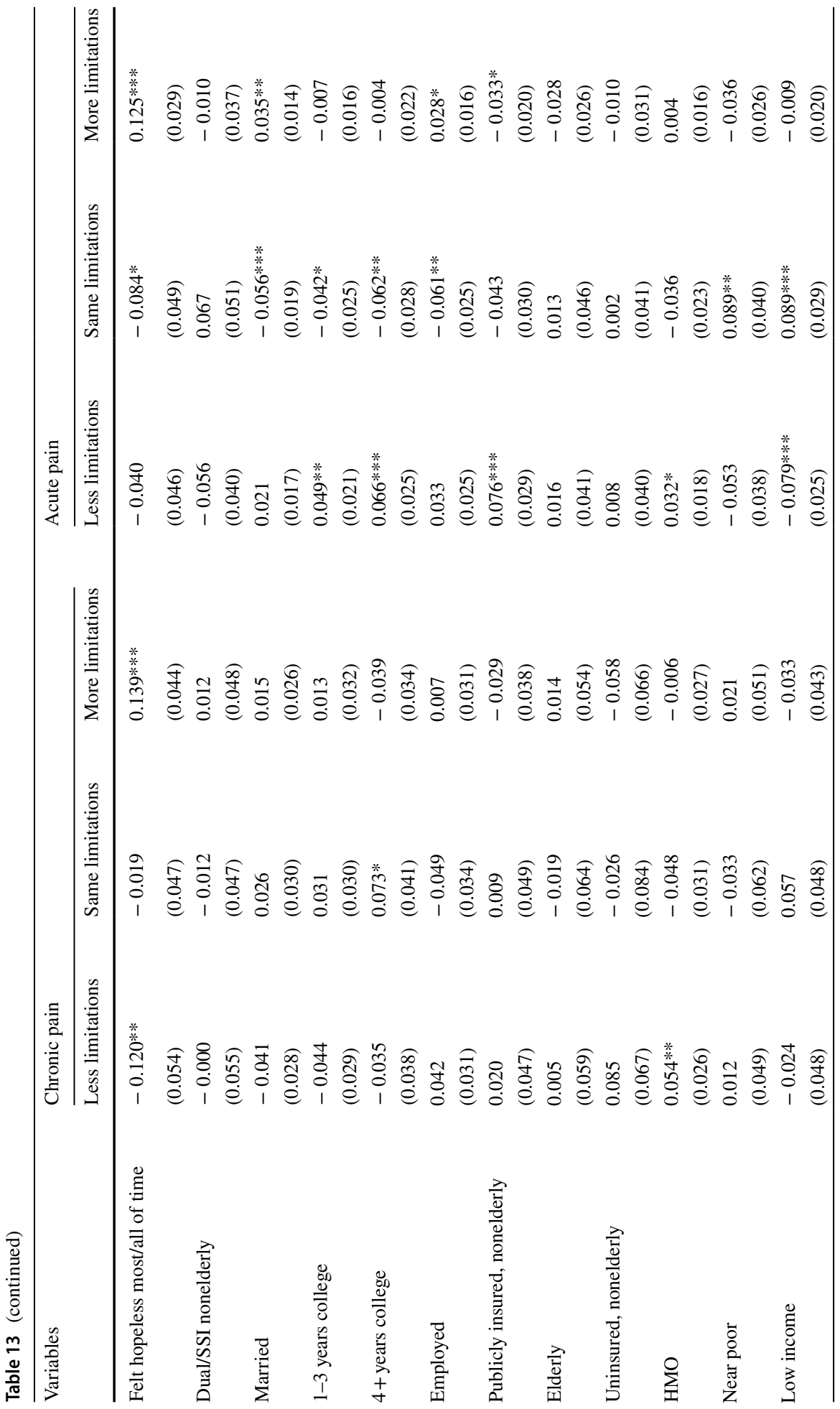




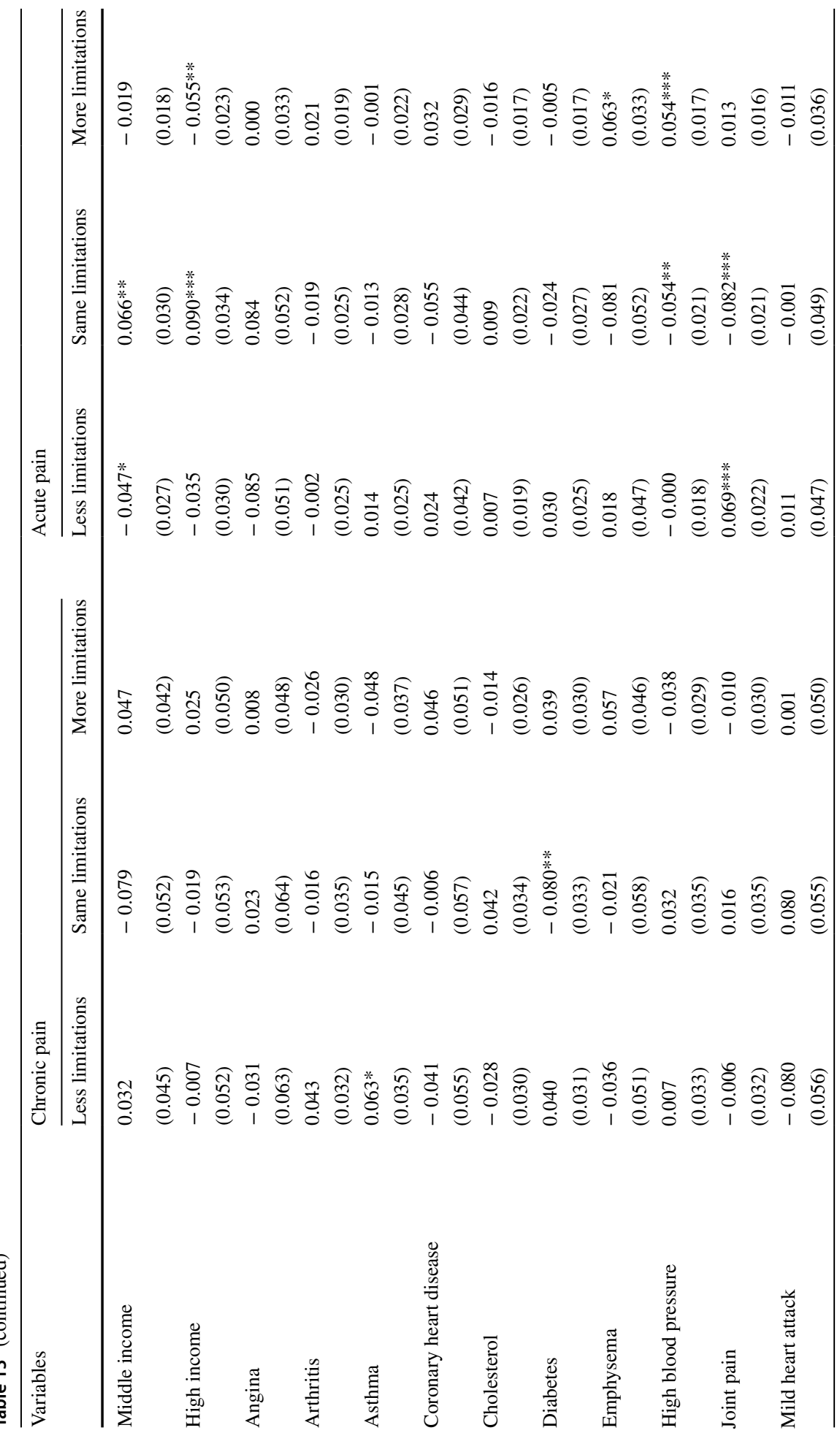




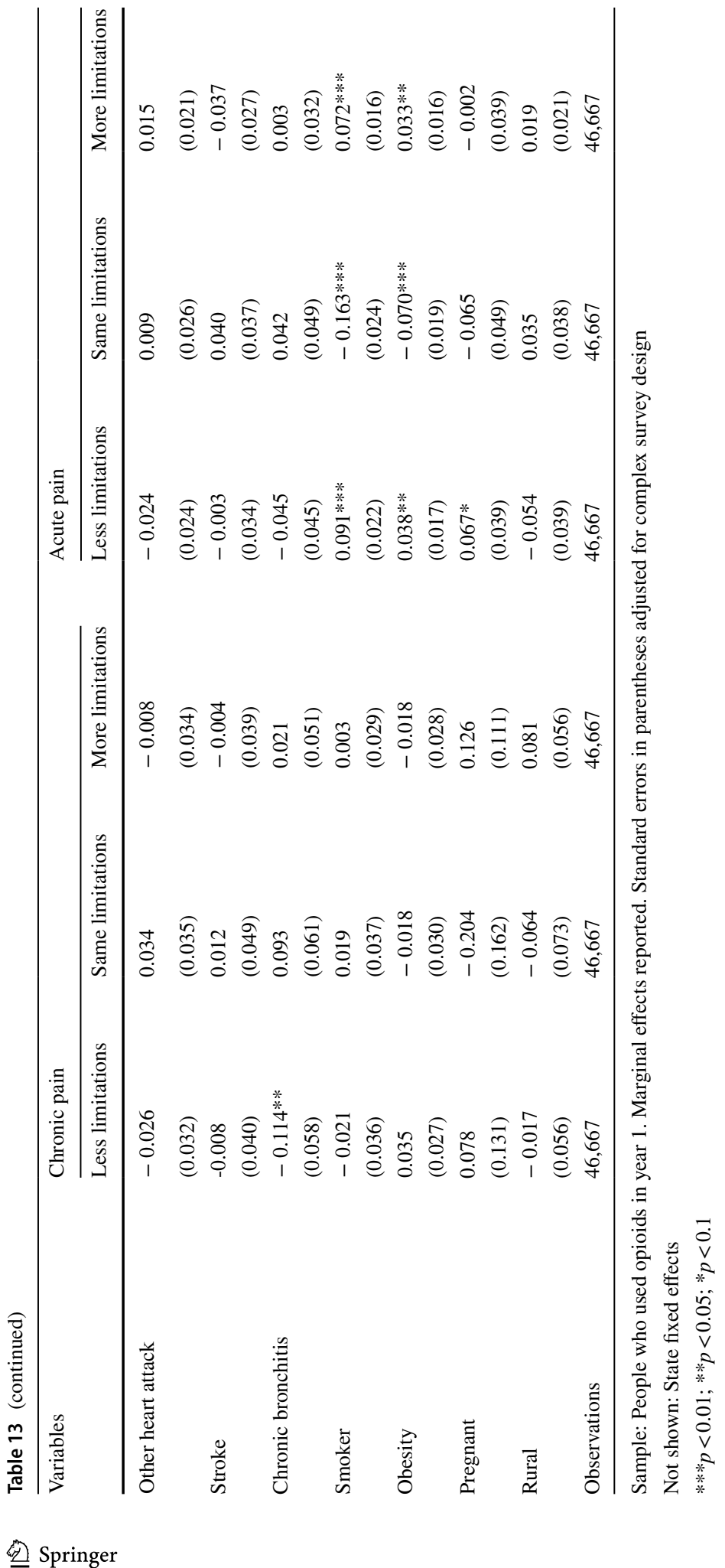




\section{References}

Adams, J. M., \& Giroir, B. P. (2019). Opioid prescribing trends and the Physician's role in responding to the public health crisis. JAMA Internal Medicine, 179(4), 476-478.

Agency for Healthcare Research and Quality. (2020a). Nonopioid pharmacologic treatments for chronic pain. Research Protocol. Rockville, MD: https://effectivehealthcare.ahrq.gov/products/nonopioid-chron ic-pain/protocol (accessed 11 Mar 2020).

Agency for Healthcare Research and Quality. (2020b). About the six building blocks program. Rockville, MD. https://www.ahrq.gov/professionals/prevention-chronic-care/improve/six-building-blocks.html (accessed 11 Mar 2020).

Alghnam, S., \& Castillo, R. (2017). Traumatic injuries and persistent opioid use in the USA: Findings from a nationally representative survey. Injury Prevention, 23, 87-92.

Baker, D. W. (2017). The Joint Commission's pain standards: origins and evolutions. The Joint Commission.

Ballantyne, J. C., \& Sullivan, M. D. (2015). Intensity of chronic pain-the wrong metric. New England Journal of Medicine, 373(22), 2098-2099.

Bao, Y., Wen, K., Johnson, P., Jeng, P. J., Meisel, Z. F., \& Schackman, B. R. (2018). Assessing the impact of state policies for prescription drug monitoring programs on high-risk opioid prescriptions. Health Affairs, 37(10), 1596-1604.

Bernard, D., Encinosa, W., Cohen, J., \& Fang, Z. (2020). Patient factors that affect opioid use among adults with and without chronic pain. Research in Social and Administrative Pharmacy. https://doi.org/10. 1016/j.sapharm.2020.07.036

Bernard, D., Machlin, S. R., Fang, Z., \& Cohen, J. (2019). Average annual opioid use among adults treated for conditions associated with chronic pain versus other conditions, 2013-2015. Research Findings \#43. Agency for Healthcare Research and Quality, Rockville, MD. https://meps.ahrq.gov/ data_files/publications/rf43/rf43.pdf (accessed 11 Mar 2020).

Bohnert, A. S., Guy, G. P., Jr., \& Losby, J. L. (2018). Opioid prescribing in the United States before and after the Centers for Disease Control and Prevention's 2016 opioid guideline. Annals of Internal Medicine, 169(6), 367-375.

Brat, G. A., Agniel, D., Beam, A., et al. (2018). Postsurgical prescriptions for opioid naive patients and association with overdose and misuse: Retrospective cohort study. BMJ, 360, j5790.

Brennan, F. (2015). The US congressional "Decade on Pain Control and Research" 2001-2011: A review. Journal of Pain and Palliative Care Pharmacotherapy, 29(3), 212-227.

Califf, R. M., Woodcock, J., \& Stephen Ostroff, S. (2016). A proactive response to prescription opioid abuse. New England Journal of Medicine, 14(374), 1480-1485.

Centers for Disease Control and Prevention. (2017). Vital Signs. Opioid prescribing where you live matters. https://www.cdc.gov/vitalsigns/opioids/index.html

Centers for Disease Control and Prevention, National Center for Injury Prevention and Control. (2020). U.S. Opioid Dispensing Rate Maps. Dec 7, 2020 https://www.cdc.gov/drugoverdose/maps/rxratemaps.html

Chou, R., Deyo, R., Devine, B., Hansen, R., Sullivan, S., Jarvik, J. G., Blazina, I., Dana, T., Bougatsos, C., Turner, J. (2014). The effectiveness and risks of long-term opioid treatment of chronic pain [Evidence Report/Technology Assessment No. 218]. Agency for Healthcare Research and Quality. http://www.effectivehealthcare.ahrq.gov/ehc/products/557/1971/chronic-pain-opioid-treatmentreport-141007.pdf (accessed 31 Jan 2020).

Chou, R., Turner, J. A., Devine, E. B., et al. (2015). The effectiveness and risks of long-term opioid therapy for chronic pain: A systematic review for a National Institutes of Health Pathways to Prevention Workshop. Annals of Internal Medicine, 162, 276-286.

Chua, K.-P. \& Kimmel, L. (2020). Opioid Prescribing limits for acute pain. Institute for Healthcare Policy and Innovation, University of Michigan. https://effectivehealthcare.ahrq.gov/products/chron icpain-opioid-treatment/research.

Cicero, T. J., Ellis, M. S., Surratt, H. L., \& Kurtz, S. P. (2014). The changing face of heroin use in the United States: A retrospective analysis of the past 50 years. JAMA Psychiatry, 71(7), 821-826.

Cohen, S. (2000). Sample Design of the 1997 medical expenditure panel survey household component, methodology report 11, AHRQ Pub. No. 01-0001. Rockville (MD): Agency for Healthcare Research and Quality.

Compton, W. M., \& Jones, C. M. (2019). Epidemiology of the US opioid crisis: The importance of the vector. Annals of the New York Academy of Sciences, 1451(1), 130-143.

Council of Economic Advisors. (2019). The full cost of the opioid crisis: \$2.5 Trillion over 4 years. https:// trumpwhitehouse.archives.gov/articles/full-cost-opioid-crisis-2-5-trillion-four-years/ 
Council of Economic Advisors. (2020). The economic report of the President. Feb 2020. https://www.nber. org/sites/default/files/2020-05/ERP-2020.pdf

Currie, J. \& Schwandt, H. H. (2020). The Opioid epidemic was not caused by economic distress but by factors that could be more rapidly addressed. NBER Working Paper 27544.

Dasgupta, N., Beletsky, L., \& Ciccarone, D. (2018). Opioid crisis: No easy fix to its social and economic determinants. AJPH, 108(2), 182-186.

Davis, C. S., Lieberman, A. J., Hernandez-Delgado, H., \& Suba, C. (2019). Laws limiting the prescribing or dispensing of opioids for acute pain in the United States: A national systematic legal review. Drug and Alcohol Dependence, 194, 166-172.

Delcher, C., Slavova, S., Wang, Y. M. S., \& Henry, S. G. (2019). Opioid prescribing before and after the Centers for disease control and prevention's 2016 opioid guideline, letter to the editor. Annals of Internal Medicine, 170(8), 581-582.

Dowell, D., Haegerich, T. M., \& Chou, R. (2016). CDC guideline for prescribing opioids for chronic painUnited States, 2016. JAMA, 315(15), 1624-1645.

Dowell, D., Haegerich, T., \& Chou, R. (2019). No shortcuts to safer opioid prescribing. New England Journal of Medicine, 380(24), 2285-2287.

Edlund, M. J., Martin, B. C., Russo, J. E., DeVries, A., Braden, J. B., \& Sullivan, M. D. (2014). The role of opioid prescription in incident opioid abuse and dependence among individuals with chronic noncancer pain: The role of opioid prescription. Clinical Journal of Pain, 30(7), 557-564.

Ellis, R., \& McGuire, T. (1986). Provider behavior under prospective reimbursement: Cost sharing and supply. Journal of Health Economics, 5, 129-151.

Hedegaard, H., Miniño, A. M., \& Warner, M. (2020). Drug overdose deaths in the United States, 19992019. NCHS Data Brief, no. 394. Hyattsville, MD: US Department of Health and Human Services, CDC, National Center for Health Statistics; https://www.cdc.gov/nchs/data/databriefs/db394-H.pdfpdf icon.

Haffajee, R. L., Mello, M. M., Zhang, F., Zaslavsky, A. M., Larochelle, M. R., \& Wharam, J. F. (2018). Four states with robust prescription drug monitoring programs reduced opioid dosages. Health Affairs, 37(6), 964-974.

Heins, S. E., Feldman, D. R., Bodycombe, D., et al. (2016). Early opioid prescription and risk of long-term opioid use among US workers with back and shoulder injuries: A retrospective cohort study. Injury Prevention, 22, 211-215.

Hill, S.C., Roemer, M., Stagnitti, M.N. (2014) Outpatient prescription drugs: Data Collection and editing in the 2011 medical expenditure panel survey. Methodology Report \#29. March 2014. Agency for Healthcare Research and Quality, Rockville, MD. http://meps.ahrq.gov/mepsweb/data_files/publications/ mr29/mr29.pdf (accessed 11 Mar 2020).

Hincapie-Castillo, J. M., Goodin, M., Possinger, M.-C., Usmani, S. A., \& Vouri, S. M. (2020). Changes in opioid use after Florida's restriction law for acute pain prescriptions. JAMA Network Open, 3(2), e2002.

Hoppe, J. A., Howard, K., \& Kennon, H. (2015). Association of emergency department opioid initiation with recurrent opioid use. Annals of Emergency Medicine, 65, 493-499.

Jones, C. M. (2013). Heroin use and heroin use risk behaviors among nonmedical users of prescription opioid pain relievers-United States, 2002-2004 and 2008-2010. Drug and Alcohol Dependence, 132(1-2), 95-100.

Kaestner, R. \& Ziedan E. (2019). Mortality and socioeconomic consequences of prescription opioids: Evidence from state policies. National Bureau of Economic Research. Cambridge, MA: Working Paper 26135.

Kang, N. (2020). Once The coronavirus pandemic subsides, the opioid epidemic will rage. Health Affairs Blog, April 15, 2020.

Keefe, P. R. (2017). The family that built an empire of pain. The New Yorker. 17 Oct 2017.

Lankenau, S. E., Teti, M., Silva, K., Bloom, J. J., Harocopos, A., \& Treese, M. (2012). Initiation into prescription opioid misuse amongst young injection drug users. The International Journal on Drug Policy, 23(1), 37-44.

Maclean, J. C., Mallatt, J., Ruhm C. J. \& Simon, K. (2020). Economic studies on the opioid crisis: A review. NBER Working paper 28067.

Manchikanti, L., Kaye, A. M., Knezevic, N. N., et al. (2017). Responsible, safe, and effective prescription of opioids for chronic non-cancer pain: American Society of Interventional Pain Physicians (ASIPP) Guidelines. Pain Physician, 20(2S), S3-S92.

Mattson, C. L., Tanz, L. J., Quinn, K., Kariisa, M., Patel, P., \& Davis, N. L. (2021). Trends and geographic patterns in drug and synthetic opioid overdose deaths-United States, 2013-2019. Morbidity and Mortality Weekly Report, 70(6), 202-207. https://doi.org/10.15585/mmwr.mm7006a4 
Max, M. B. (1990). Improving outcomes of analgesic treatment: Is education enough? Annals of Internal Medicine, 113(11), 885-889.

McGuire, T. G., \& Pauly, M. V. (1991). Physician response to fee changes with multiple payers. Journal of Health Economics, 10(4), 385-410. https://doi.org/10.1016/0167-6296(91)90022-f PMID: 10117011.

Mezei, L., \& Murinson, B. B. (2011). Pain education in North American medical schools. The Journal of Pain, 12, 1199-1208.

Muhuri, P. K., Gfroerer, J. C., \& Davies, M. C. (2013). Substance abuse and mental health services administration. Associations of nonmedical pain reliever use and initiation of heroin use in the United States. CBHSQ Data Review. Accessed October 8, 2015. https:/www.samhsa.gov/data/sites/default/files/ DR006/DR006/nonmedical-pain-reliever-use-2013.htm

Olaughlin, C., \& Brantlye, K. (2018). Trends in opioid Use: History, background, and origins of the epidemic. Avalere Health. https://avalere.com/insights/trends-in-opioid-use-history-background-and-origi ns-of-the-epidemic (Accessed 11 Nov 2019).

Olfson, M., Wang, S., Wall, M. M., \& Blanco, C. (2020). Trends in opioid prescribing and self-reported pain among US adults. Health Affairs (millwood), 39(1), 146-154.

Paulozzi, L. J., Zhang, K., Jones, C. M., \& Mack, K. A. (2014). Risk of adverse health outcomes with increasing duration and regularity of opioid therapy. Journal of the American Board of Family Medicine, 27(3), 329-338.

Perry, S., \& Heidrich, G. (1982). Management of pain during debridement: A survey of US burn units. Pain, $13,267-280$

Porter, J., \& Jick, H. (1980). Addiction rare in patients treated with narcotics. New England Journal of Medicine, 302, 1.

National Conference of State Legislatures. (2019). Prescribing Policies: States confront opioid overdose epidemic. Washington, DC. www.ncsl.org/research/health/prescribing-policies-states-confront-opioidoverdose-epidemic.aspx (Accessed 9 Sept 2019).

Rosenberg, J. M., Bilka, B. M., Wilson, S. M., \& Spevak, C. (2018). Opioid therapy for chronic pain: Overview of the 2017 US Department of Veterans Affairs and US Department of Defense Clinical Practice Guideline. Pain Medicine, 19(5), 928-941. https://doi.org/10.1093/pm/pnx203

Rudd, R. A., Seth, P., David, F., \& Scholl, L. (2016). Increases in drug and opioid-involved overdose deaths-United States, 2010-2015. MMWR. Morbidity and Mortality Weekly Report, 65(50-51), 1445-1452.

Rutkow, L., \& Vernick, J. S. (2017). more states should regulate pain management clinics to promote public health. AJPH, 107(2), 240-243.

Ryder, S.-A., \& Stannard, C. F. (2005). Treatment of chronic pain: Antidepressant, antiepileptic and antiarrhythmic drugs. Continuing Education. Anaesthesia, Critical Care and Pain, 5(1), 18-21.

Sacks, D. W., Hollingsworth, A., Nguyen, T. D., \& Simon, K. I. (2019). Can policy affect initiation of addictive substance use? Evidence from opioid prescribing. Cambridge, MA: NBER Working Paper No. 25974.

Schieber, L. Z., Guy, G. P., Seth, P., Young, R., Mattson, C. L., Mikosz, C. A., \& Schieber, R. A. (2019). Trends and Patterns of geographic variation in opioid prescribing practices by State, United States, 2006-2017. JAMA Network Open, 2(3), e190665.

Scholl, L., Seth, P., Kariisa, M., Wilson, N., \& Baldwin, G. (2019). Drug and opioid-involved overdose deaths-United States, 2013-2017. Morbidity and Mortality Weekly Report, 67(51-52), 1419. https:// doi.org/10.15585/mmwr.mm675152e1

Schuchat, A., Houry, D., \& Guy, G. P. (2017). New data on opioid use and prescribing in the United States. JAMA, 318(5), 425-426. https://doi.org/10.1001/jama.2017.8913

Shah, A., Hayes, C. J., \& Martin, B. C. (2017). Characteristics of initial prescription episodes and likelihood of long-term opioid use: United States, 2006-2015. Morbidity and Mortality Weekly Report, 66(10), 265-269.

Song, Z. (2017). Mortality Quadrupled among opioid-driven hospitalizations, notably within lower-income and disabled white populations. Health Affairs, 36(12), 2054-2061.

Tian, T. Y., Zlaveta, I., \& Anderson, D. R. (2013). Using electronic health records data to identify patients with chronic pain in a primary care setting. Journal of the American Medical Informatics Association, 20(e2), e275-e280.

Van Zee, A. (2009). The promotion and marketing of oxycontin: Commercial triumph, public health tragedy. American Journal of Public Health, 99(2), 221-227.

Vowles, K. E., McEntee, M. L., Julnes, P. S., Frohe, T., Ney, J. P., \& van der Goes, D. N. (2015). Rates of opioid misuse, abuse, and addiction in chronic pain: A systematic review and data synthesis. Pain, 156(4), 569-576. https://doi.org/10.1097/01.j.pain.0000460357.01998.f1 
Wen, H., Hockenberry, M., Jeng, P. J., \& Bao, Y. (2019). Prescription drug monitoring program mandates: Impact on opioid prescribing and related hospital use. Health Affairs, 38(9), 1550-1556.

Wen, H., Schackman, B. R., Aden, B., \& Bao, Y. (2017). States with prescription drug monitoring mandates saw a reduction in opioids prescribed to Medicaid enrollees. Health Affairs, 36(4), 733-741.

Yanni, L. M., McKinney-Ketchum, J. L., Harrington, S. B., et al. (2010). Preparation, confidence, and attitudes about chronic noncancer pain in graduate medical education. Journal of Graduate Medical Education, 2, 260-268.

Publisher's Note Springer Nature remains neutral with regard to jurisdictional claims in published maps and institutional affiliations. 